\title{
Barriers to industrial energy efficiency in foundries: a European comparison
}

Andrea Trianni, Enrico Cagno, Patrik Thollander and Sandra Backlund

The self-archived postprint version of this journal article is available at Linköping University Institutional Repository (DiVA):

http:/ / urn.kb.se/ resolve?urn=urn:nbn:se:liu:diva-86548

N.B.: When citing this work, cite the original publication.

Trianni, A., Cagno, E., Thollander, P., Backlund, S., (2013), Barriers to industrial energy efficiency in foundries: a European comparison, J ournal of Cleaner Production, 40, 161-176.

https:// doi.org/ 10.1016/j.jclepro.2012.08.040

Original publication available at:

https:// doi.org/ 10.1016/j.jclepro.2012.08.040

Copyright: Elsevier

http:// www.elsevier.com/

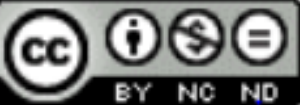




\section{Barriers to industrial energy efficiency in foundries: a European comparison}

\section{Andrea Trianni*,}

Politecnico di Milano, Dept. Management, Economics and Industrial Engineering,

Piazza Leonardo da Vinci 32 - 20133 Milan (Italy), andrea.trianni@polimi.it

\section{Enrico Cagno,}

Politecnico di Milano, Dept. Management, Economics and Industrial Engineering, Piazza Leonardo da Vinci 32 - 20133 Milan (Italy), enrico.cagno@polimi.it

\section{Patrik Thollander,}

Department of Management and Engineering, Linköping University, SE-581 83 Linköping, Sweden, patrik.thollander@liu.se

\section{Sandra Backlund,}

Department of Management and Engineering, Linköping University, SE-581 83 Linköping, Sweden, sandra.backlund@liu.se 


\section{Abstract:}

According to recent studies, the 20\% European improvement in energy efficiency will not be achieved with current trends, even with the adoption of present policies to reduce primary energy use. This is due to the existence of several barriers that hinder the adoption of the energy-efficient technologies and practices. A relevant contribution to improved energy efficiency could come from the industrial sector, due to its relevance on total energy use. This study therefore addresses barriers within the European foundry industry, a major industrial energy user and a strategic player for the European economy. The research investigates the barriers to energy efficiency at 65 foundries, several of them small and medium-sized enterprises (SMEs), highlighting the critical problems and difficulties by evaluating the socio-technical frameworks against which the barriers have been categorized. Findings show that the greatest perceived barriers are the perception of the lack of resources to be devoted to improving energy efficiency, and the existence of other priorities such as the importance of guaranteeing business continuity. The study has also performed a preliminary analysis of the factors that might affect the perception of barriers. In particular, looking at size, smaller enterprises show a greater perception of the barriers than larger ones, mainly due to several organizational issues, but with effect on behavioural ones, that tend to downgrade energy efficiency to a peripheral issue. The study has also highlighted differences by type of alloy characterizing foundries, taken as proxy of the process complexity. Indeed, enterprises with simpler production processes tend to perceive higher barriers to energy efficiency, showing the need to identify effective means to promote energy efficiency among those enterprises. Moreover, the analysis has pointed out that performing energy audits brings more awareness to the enterprises, highlighting the effective existing difficulties in improving their energy efficiency. This result seems to be relevant since it shows the need for the research to analyse the awareness to energy efficiency in greater depth and 
develop the most effective policies to increase it at industrial level. Finally when looking at the country in which foundries operate, German enterprises tend to suffer from the barriers far less than the average, whilst a totally different behaviour can be observed for Swedish ones. These preliminary findings open the research to investigate in greater depth the factors leading to a different perception of barriers, and also the domestic policies that have led to those results. Moreover, the study opens to investigate which means, i.e. drivers, might be more effectively exploited at European level to promote industrial energy efficiency.

Keywords: industrial energy efficiency, barriers, foundries.

\section{Introduction}

Over the last 10 years the world has been facing substantial growth in primary energy demand, with an inversion of the role of non-OECD economies (mainly China and India) that, since 2008, have surpassed the demand of the developed economies.

In particular, the projections for 2035 provided by the most relevant international agencies (Energy Information Administration 2010) forecast that Chinese primary energy use will be almost double that of the U.S.A.

Moreover, due to heavy reliance on fossil fuels, the emissions of greenhouse gases (GHG), in particular $\mathrm{CO}_{2}$, in developing countries (usually called “coal economies”) are predicted to grow from 30 billion metric tons to more than 40 billion metric tons: in this regard studies (IEA/OECD 2009) estimate that China will surpass the emissions of the United States, the European Union and Japan by 2028. Energy has thus become a global concern on the public agenda. 
Several policies, and in particular the European Directive 2009/28-33 (European Council 2009), aim at tackling these issues by 2020 through a $20 \%$ reduction in GHG emissions, a $20 \%$ increase in the share of primary energy from renewable energy sources, and a $20 \%$ reduction in energy use compared to the primary energy level in 2005.

The efforts made by European countries in the three streams are producing contradictory results: in particular, if current trends continue, if the objectives of reducing GHG emissions and increasing the share of renewables seem to be achievable, the same cannot be said as regards the reduction in energy use. Indeed, with current trends, only 10\% will be reached (European Commission 2011). This highlights the strategic role of improved energy efficiency, which should be promoted at any level in the residential, industrial, commercial and transportation sectors.

One important player in improving energy efficiency is the industrial sector, which is responsible of about 30\% of the total energy end-use (Eurostat 2011), and for which energy efficiency could not only represent a viable solution for reducing energy costs, rather than an opportunity to be really exploited, since it is "linked to commercial, industrial competitiveness and energy security benefits, as well as increasingly to environmental benefits” (Patterson 1996). Within this sector, a remarkable role is played by the so-called energy-intensive industries that account for most of the industrial energy use (Energy Information Administration 2011). Among those, it would be quite relevant to improve energy efficiency in European foundries, that cover alone $14 \%$ of the total industrial consumption, and where the majority consist of small- and medium-sized enterprises. As stated by e.g. Shipley and Elliot (Shipley and Elliott 2001) these industrial small and medium-sized enterprises have in general a more limited capacity to target improved energy efficiency then larger ones, i.e. set up and in- 
house energy management programs, adopt an energy management system etc.. Moreover, in many countries the foundry industry represent a strategic sector for the domestic economies. These two facts, high energy-intensity, and the fact that the majority of the foundries are not large in size makes the European foundry industry of particular interest to study in regard to improved energy efficiency and barriers affecting this.

In order to promote energy efficiency, it is quite relevant to have a detailed picture of the most effective technologies to be deployed. In this regard, the topic has been widely assessed, providing several insights especially for process-specific technologies (Zhang \& Wang 2008; Worrell \& Biermans 2005; Worrell 1995; Worrell et al. 1997).

Nonetheless, in the same manner it is crucial to understand what are the obstacles to the adoption of an energy-efficient technology, i.e. barriers to energy efficiency investments. In fact, even if several efforts have already been made to study barriers to improved energy efficiency, strong opportunities to improve energy efficiency can nonetheless be observed (Worrell et al. 2010), providing clear evidence of the still existence of barriers to energy efficiency.

An operational approach to studying barriers to energy efficiency within foundries is therefore really needed: this approach would enable enterprises to understand the difficulties they encounter when undertaking investments in energy-efficient technologies. Moreover, policy-makers would benefit from the results of empirical investigations to detect the major barriers in order to promote the most effective policies for the adoption of energy-efficient technologies (Fleiter et al. 2011). Nonetheless, in order to achieve the effectiveness of a future energy efficiency policy, it would be important to better detail which might be the factors able to modify barriers, thus enabling policies to be tailored according to firm's characteristics. In fact, in literature, 
although for other sectors, factors as firm’s size (Trianni \& Cagno 2012) and having conducted previously an energy audit (Schleich 2004), have proved to have a considerable influence in modifying the perception of barriers to investment in energyefficient technologies.

Therefore, stemming from those considerations, our research has been focused on providing a preliminary insight into barriers to energy efficiency in European foundries, trying to point out commonalities and differences considering several firm's characteristics, such as the firm's size, the technologies adopted, having previously performed an energy audit, and the country in which the foundries operate, in order to provide, at European level, some pieces to the puzzle.

The paper has been structured as follows: in Section 2 we report the theoretical background of the research, highlighting previous literature and open issues, detailing in Section 3 the methodology adopted in this study. In Section 4 we present the results and a discussion, followed by our conclusions and suggestions for future research in the final section.

\section{Theoretical background}

As aforementioned, the literature on barriers to energy efficiency is quite extensive. Indeed, the topic has been widely discussed since the late '70s, when, after the oil crisis of 1973, the debate on the appropriate use of resources (energy included) arose.

In particular as regards the economic approach to barriers, we can appreciate the contribution by Hirst and Brown (Hirst \& M. Brown 1990), who detailed a framework for characterization of the market barriers, distinguishing between "structural" barriers, such as the distortion in fuel prices, uncertainty about fuel prices, government fiscal and regulatory policies, codes and standards, and the so-called "behavioural” barriers, such 
as the attitude of decision-makers or agents towards energy efficiency, the perceived risk of energy efficiency investments, information gaps (either in the content or in the form of information), and misplaced incentives to apply energy-efficient technologies and practices.

Brown (Brown 2001), conducted a literature review of existing barrier studies, describing several market failures. For more details of the scientific debate about the distinction between market barriers and market failures, which is out of scope for this study, readers are referred to, for example, (Sutherland 1996; Sanstad \& Howarth 1994; Koomey \& Sanstad 1994; Howarth \& Andersson 1993; Sanstad et al. 1993), as misplaced incentives with the "principal-agent" problem, distortion in fiscal and regulatory policies, unpriced costs as externalities, unpriced public goods as energy, insufficient and incorrect information. Brown has also highlighted the existence of other market barriers, such as the low priority given to energy issues, the capital market barriers, and the incomplete markets for energy efficiency.

Other authors, like Stern (Stern \& Aronson 1984) and DeCanio (DeCanio 1993), have looked thoroughly at the identification of the behavioural aspects related to the barriers to energy efficiency, thus leading to the adoption of approximate criteria (or routines) to evaluate the profitability of energy-efficient technologies. Or, as Hewett notes (Hewett 1998), the combined effect of treating gains differently to losses, giving greater weighting to certain outcomes with respect to those that are uncertain, thus detailing the inertia barrier.

Nonetheless, the structure of the organization plays an important role in the process of evaluating the adoption of energy-efficient technologies. As highlighted by DeCanio (DeCanio 1998), several organizational and institutional factors over and above the economic factors, also influence the paybacks. In this case, DeCanio has noted that 
neither the equipment supplier nor the team who install the equipment can be ignored, and, in some cases, may represent an obstacle to the adoption of proven energy-efficient technologies.

It is clear and widely known, as suggested by this brief overview of the literature, that from a theoretical viewpoint, several disciplines have contributed to addressing the barriers to industrial energy efficiency: economic approaches, organizational and behavioural studies, and several players can be identified when investigating the barriers, as thoroughly described by the Third Assessment Report of the Intergovernmental Panel for Climate Change (IPCC) (IPCC 2001) and by Reddy (Reddy 1991).

The greatest contribution to the scientific debate, made by Sorrell et al., is to try to categorize the existing barriers to energy efficiency in a taxonomy, collecting the most important contributions that have emerged in the literature (Sorrell et al. 2000), with further revisions in 2004 (Sorrell et al. 2004) and 2010 (Sorrell et al. 2010), and dividing them according to the theoretical approach they follow, either economic, organizational, or behavioural. Taking several elements from Jaffe and Stavins (Jaffe \& Stavins 1994) and Golove and Eto (Golove \& Eto 1996), Sorrell et al. have therefore proposed a categorization of fifteen barriers, as shown in Table I.

This taxonomy can be considered a key reference in the literature at this point in time.

Table I. Barriers to energy efficiency: the Sorrell et al. taxonomy (Sorrell et al. 2000). 
If the literature on theoretical studies about barriers to industrial energy efficiency is huge, the same cannot be said for the empirical investigations on the topic. Indeed, only few studies have so far provided empirical results concerning barriers to industrial energy efficiency. In this respect, the contribution provided by Sardianou (Sardianou 2008) on barriers to energy efficiency investments in Greece is of interest. Another study by Schleich has also drawn an interesting comparison between the commercial and service sectors in Germany (Schleich 2009). A recent study by Trianni and Cagno (Trianni \& Cagno 2012) makes a preliminary analysis of the barriers in Italian nonenergy intensive small and medium-sized manufacturing enterprises, providing several insights into the relationships between the operational barriers.

Other relevant empirical contributions in the literature have been provided by Rohdin et al. (Rohdin et al. 2007), who have tried to make a link between the operational barriers and the theoretical ones, according to the taxonomy proposed by Sorrell et al., applying the study to Swedish foundries.

During the interviews, the authors obtained a description of the firm's operational barriers when undertaking an investment in energy-efficient technology, which they then classified according to the taxonomy. Nonetheless, in doing so, they referred the issue exclusively to a main theoretical barrier. It is apparent that the operational barriers do not necessarily belong to a single theoretical one. Therefore, as partially suggested by the study made by Sorrell et al. in which they explicitly refer to possible overlaps and interactions between theoretical barriers, it would be quite interesting to relate the operational barriers to more theoretical ones. For this reason, although the study by Rohdin et al. represents a first relevant milestone in operatively addressing the topic, it may neglect some secondary effects that in combination could significantly affect the 
importance of the barriers. These findings are further supported by Palm and Thollander (Palm \& Thollander 2010).

\section{Methodology}

For this reason, in our study, starting from the approach proposed by Rohdin et al., we have firstly proposed a substantial list of operational barriers, i.e. some practical aspects of the difficulties enterprises encounter when coping with investments in energyefficient technologies. We have also proposed a discussion of the operational barriers that considers not only the primary theoretical barrier, but, where applicable, also the secondary barriers to which the questions refer. In addition, we have discussed the difficulties taking into account several important characteristics of the sample, detailing commonalities and differences between countries, firms’ size, energy expenditures, etc. To do this, it is clear that the first step is to link the list of operational barriers to the theoretical barriers, as reported in Table II, and then perform the analyses and observe the differences, as presented in the results section.

One of the main purposes of our study was to point out the relevance given to energy efficiency in the operations. For this reason, as can be inferred looking at Table II, several operational barriers can be referred to the Power theoretical one ( 7 as primary, 2 as secondary). Moreover, it is quite relevant to note, when asking operational barriers to enterprises (thus having an empirical feedback of the theoretical barriers) that the Power barrier, as by definition, considers a production system as a political system, in which conflicts take place. Therefore, although quite difficult to be separated, nonetheless this might have a non-negligible effect on the behaviour of single agents and on the structure that takes the decisions on investments in energy-efficient technologies. 
Table II. Operational barriers and theoretical barriers according to Sorrell et al. (Sorrell et al. 2000).

Within a wider scope of getting a broader picture of the foundry sector among several European countries, the explorative nature of the study and the multiple sites investigated drove this study to be carried out as case-studies using semi-structured interviews and questionnaires.

Firstly, in collaboration with national foundry associations and research institutes in each country, a questionnaire has been sent to 831 foundries, via mail or postal services. The complete study embraces several aspects regarding key figures related to energy and production as well as barriers to increasing energy efficiency. The questionnaire reached a response rate of 125 foundries, 65 of which answered the questionnaire completely. Looking at the response rate, it is possible to observe $8 \%$ complete answers, $15 \%$ including the ones which were partly answered. Comparing this response frequency with previous research in for example the Netherlands yields that the response frequency can be considered high (Velthuijsen 1993; de Groot et al. 2001), while comparison with previous research in Sweden indicates a normal response frequency (Thollander \& Ottosson 2010; Thollander \& Ottosson 2008). In order to evaluate the answers, a Likert scale was established, ranging from 1 to 5 as follows: not relevant (1), fairly relevant (2), relevant (3), very relevant (4), and absolutely relevant (5).

The responses to the questionnaires have been considerably integrated with interviews to the people responsible for energy issues at their site, moreover helping to clarify the 
content of the responses. Doing that, we have developed a set of questions or "stimuli" to be proposed to interviewees, making it easy on the one side to repeat ("replicate") the interview, on the other side to compare the available information. Moreover, as suggested by Russell (Russell 1988) this structure results to be quite useful in situations where the researcher can only meet the informant once and hence the interview is not likely to be repeated.

Although context effects can never be avoided, the additional questions to integrate and clarify the needed information on barriers have been hold constant across all respondents. This, as indicated by Patton (Patton 1991), is important for minimizing the impact of context effect for which the answers given to a survey can depend on the nature of preceding questions.

Combining the questionnaires with interviews allowed us to have a more reliable information, since a positive relationship between interviewer and interviewee enables people to talk about something in detail and depth. In fact, thanks to the interviews it was possible to understand several issues more in depth, starting sometimes from little direction by interviewers. The result of this activity has led to build 65 cases studied among European foundries, a number indeed quite adequate to the purpose of "analytic generalization” which is claimed to be properly supported by the collection of around 10 cases, as suggested by Yin (Yin 2003).

For what concerns the size, the enterprises have been classified into small (SEs), medium (MEs), and large enterprises (LEs), according to the European Classification (European Council 2003), as reported in Table III. Other important information to characterize the enterprises is related to their production processes, i.e. the type of material (alloy) cast, and their energy consumption. In particular, four broad categories of cast materials have been identified: cast iron, cast steel, copper and aluminium. 
Moreover, we have divided the enterprises according to the "Audit” factor, that aims at highlighting if the conduction of an energy audit in the past might have a role in the perception of barriers to energy-efficient technologies. Finally, aiming to perform several comparisons between European countries, identifying commonalities and differences, the study has involved foundries located in Finland, France, Germany, Italy, Poland, Spain and Sweden in late 2010 and the beginning of 2011.

Table III. Description of the sample by Firm’s size vs. Alloy, Audit and Country.

By looking at Table III, we can see that about half of the sample is composed by MEs. Moreover, when considering the alloy, the subsample of enterprises realizing copper products is quite limited (only 3 enterprises), whilst Cast Iron enterprises represent about $50 \%$ of the enterprises (33 enterprises on a total of 65 ). By a cross analysis between the factors firm's size and alloy, we can see that Cast Iron and Cast Steel are mainly medium-large enterprises (only 7 out of 47 are SEs). Moreover, considering the sample with respect to the factor "Audit", we can observe that it is homogeneous, evidence also by a cross analysis between the Audit factor and the firm's size. By looking at the factor Country, we can note that Sweden and Germany (respectively with 20 and 16 enterprises) represent more than half of the sample. Nonetheless, analyzing the factor Country with the firm's size, we can see that German enterprises are mediumlarge, whilst Swedish ones are small and medium. Always considering the Country factor, by a cross analysis with the Alloy factor we can find a concentration of both German and Swedish enterprises on Cast Iron (with respectively 12 and 9 enterprises). Finally, by looking at a cross analysis between the country and the Audit factor, it is 
possible to appreciate that both Swedish and German subsamples are more distributed towards enterprises that have previously conducted an energy audit (respectively 14 and 12 enterprises).

It should be noted that the study's design was a multiple case study and not a survey analysing data statistically. The main reason for this was that the existing number of foundries in each country and alloy type in several cases was too small, in order to analyse statistically, i.e. is too small to be statistically representative. This called for a multiple case study inspired by Yin (2003) to be chosen as the overall research design. Nonetheless, considering the explorative nature of this study (Yin, 2003), it is considered still of interest to investigate this sample of the total population of foundries, in order to get the first understandings and evidences in this sector, some of which could be further extended.

\section{Results and discussion}

\subsection{Total sample}

In Table IV it is possible to rank the barriers according to their overall average scores. As first results, two main problems can be observed:

1. The lack of resources for energy efficiency in terms of time and capital, as expressed by the barriers Lack of budget funding, Other Priorities for Capital Investments, Lack of time and other priorities, and Access to capital. Indeed, it seems reasonable to consider that energy is just one of the issues of entrepreneurs and, therefore, a compromise between the efforts devoted to energy efficiency and other activities has to be reached; 
2. The importance of guaranteeing the continuity of the business, expressed as the relevance of the barriers concerning the cost of production disruption, hassle and inconvenience, and of the barriers related to the technical risks.

Table IV. Perceived barriers - total sample - average score and frequency of responses

The two main problems that emerged reflect almost perfectly the present situation of the enterprises, hit by the financial crisis, so that they cannot devote resources to energy efficiency, but rather they are focused on keeping their businesses running. Under those circumstances, since the energy cost accounting can be an activity particularly burdensome both in terms of time and resources to be devoted, and does not provide immediately effective results in terms of energy consumption reduction. For this reason, it is reasonable to assume that it could be disregarded. Nonetheless, energy cost accounting is of importance for both accounting departments and workers in order to move the enterprise towards a more efficient energy management, it can be felt as a major issue, as shown by the average score of 3.72 .

Looking at the earlier literature, the lack of budget funding is widely perceived as a major issue, with $73 \%$ of enterprises declaring it as quite relevant (51\% as absolutely relevant). Indeed, similar results can be observed in the study by Sorrell et al. in the manufacturing sector (Sorrell et al. 2000), although conducted exclusively at LEs, and a previous study by Rohdin and Thollander for the Swedish foundry industry (Rohdin et al. 2007). Moreover, lack of capital has been highlighted as the major barrier also by the Italian manufacturing SMEs involved in the study by Trianni and Cagno (Trianni \& Cagno 2012), and in an earlier international study involving enterprises from various 
manufacturing sectors in The Netherlands, Slovak Republic and Czech Republic (Velthuijsen 1995).

We have found an interesting result when looking at the propensity to invest in energy efficiency with respect to the overall propensity to invest (i.e. other priorities of energy efficiency investments). Indeed this barrier presents an average score of 3.89 and $73 \%$ of enterprises defining it as a very or absolutely relevant barrier. The lack of propensity to invest in energy efficiency with respect to the overall propensity to invest has been widely recognized in the literature as a major issue. In particular, evidences could be found in two case studies reported in Sorrell et al. (Sorrell et al. 2004) focused respectively on seven Irish mechanical engineering enterprises and 53 UK breweries, from de Groot et al. (de Groot et al. 2001) in a cross sectorial analysis of 135 Dutch enterprises and two studies on Swedish non energy intensive manufacturing SMEs (Rohdin \& Thollander 2006; Thollander et al. 2007).

Considering the importance of the barrier Lack of Time or Other Priorities the picture is slightly different, with 65\% of the enterprises considering it as quite relevant (score of 4 or 5), but $25 \%$ only as relevant. Comparing this result with previous literature, this barrier, that has more strict links with day-to-day operations, has been highlighted as a major issue only in few empirical studies, such as Rohdin and Thollander and Thollander et al. for Swedish non energy intensive manufacturing enterprises (Rohdin \& Thollander 2006; Thollander et al. 2007), and Italian manufacturing SMEs (Trianni \& Cagno 2012; Cagno et al. 2010). Indeed, it is quite interesting to note that previous studies on foundry industry, such as Rohdin et al. (Rohdin et al. 2007), have not highlighted this as a major issue.

When looking at barriers as cost of production disruption, hassle and inconvenience, and barriers related to the technical risks, we can see that, as from Table II, they fall at 
least partially under the Hidden Costs theoretical barrier. Indeed, hidden costs have been recognized as a relevant issue by previous literature. Evidences can be found in Nichols (Nichols 2000), that compares two different approaches to the estimation of the net benefits provided by a demand-side management program that subsidizes the purchase of energy-efficient equipment. Moreover, the results seem to find confirmation in the study by Rohdin et al. (Rohdin et al. 2007) for the Swedish foundry industry, and of Thollander and Ottosson (Thollander \& Ottosson 2008) analysing 40 enterprises of the pulp and paper industry, another energy-intensive sector.

It is then worth mentioning the barriers with the lowest overall average scores:

- Conflicts of interests within the company, that presented an average score of 2.83, with a relevant impact given by the $28 \%$ of enterprises declaring it as a not relevant issue;

- Long decision chains, average score of 2.88, but with a great dispersion of results, as shown by the almost equal percentage presented by all scores;

- Cost of staff replacement, retirement and retraining, that has reported an average score of 2.95, with only $6 \%$ of enterprises declaring it as absolutely relevant.

In particular, it can be seen that those barriers (with a score lower than 3 and thus considered to be not relevant or fairly relevant) refer to the internal organizational structure, which is not at present perceived to be an obstacle to the adoption of energyefficient technologies. Indeed, here we can see again what was said above: the perceived problem of enterprises hit by the financial crisis is the lack of resources that can be devoted to energy efficiency, rather than possible internal obstacles.

Comparing the results with previous literature on empirical studies about barriers to industrial energy efficiency, we can appreciate that, differently, information issues are 
not believed as a major issue. This, although considering different samples not always focused on the industrial sector, is in contrast with several German studies, such as Gruber and Brand who investigated 500 SMEs (Gruber \& Brand 1991), and more recently by Schleich et al. and Schleich, who performed a research in industrial and service activities (Schleich \& Gruber 2008; Schleich 2009).

By looking at the correlations among barriers in Table V (highlighting those with values higher than or equal to 0.6), we cannot appreciate any interesting finding. Despite this, we can find a slightly interesting relationship between conflicts of interest within the company (Q1), lack of influence of the energy manager (Q5) and low priority given to energy management (Q8) (with a correlation coefficient slightly higher than 0.6), and the weak correlation between the lack of budget funding (Q17) and access to capital (Q23). Two reasonable explanations for both results can be drawn: the first reflects how organizational issues related to the Power barrier may affect the enterprises; the latter indicates how the budget may be reasonably affected by a difficulty in gathering the necessary capital to perform investments in energy-efficient technologies.

Nonetheless, since the overall analysis of correlations has showed very light relationships, we have the confirmation of the capability by the research to distinguish clearly the punctual operational barriers.

Table V. Perceived barriers - total sample - Analysis of correlations

Since the considerations drawn above exclusively reflect the average behaviour of the interviewed SMEs and the sample is not homogeneous for several factors (i.e. size, country, type of alloy, and previous experience of energy audits), we have performed 
several further analyses in order to evaluate what (if any) are the differences and commonalities between these factors.

\subsection{Barriers by firms' size}

When dividing the sample according to size (Table III), we can see several differences in the perceived barriers between SEs and LEs, as shown in Table VI and Figure 1. In general, SEs show higher barriers than LEs; indeed, in 10 out of 23 questions, the differences between SEs’ and LEs’ barriers are larger than 0.5.

Table VI. Perceived barriers - by firms’ size.

Figure 1. Perceived barriers - by firm's size -frequency of responses

The greatest differences are in respect of the following operational barriers:

1) Slim organization; difference of 1.19

2) Lack of time or other priorities; difference of 0.95

3) Low priority given to energy management; difference of 0.76

4) Lack of technical skills; difference of 0.69

5) Energy objectives not integrated into operating/maintenance or purchasing procedures; difference of 0.67

6) Lack of staff awareness, difference of 0.62

7) Lack of submetering; difference of 0.60

8) Difficulties in obtaining information about the energy consumption of purchased equipment difference of 0.60 
9) Access to capital difference of 0.58

10) Cost of identifying opportunities/analysing cost effectiveness and tendering; difference of 0.55

Looking at the problems that emerged from the responses, it can be seen that the sample highlights the importance of a structure for investigating and managing energy issues. In fact, the larger the enterprise, the lower the issues of having people exclusively devoted to researching energy inefficiencies and opportunities, having time for these activities, and having adequate skills to evaluate problems and solutions. It is also reasonable to assume that in LEs with people devoted to energy efficiency, it will be possible to measure the performance of the equipment in terms of energy consumption. Those considerations are strongly supported by the analyses of frequencies reported in Figure 1. In particular we can see that, for the barrier Slim organization, none of the SEs have declared that to be a not relevant or fairly relevant issue, and about two thirds of them have judged it to be at least a quite relevant issue. This finding, in comparison with the $25 \%$ of LEs that considered slim organization at least a quite relevant issue (and only $6 \%$ as absolutely relevant), makes apparent what is said above. Similar results can be observed when looking at the Lack of time and Other priorities barrier. Whilst none of the SEs has judged it as a non-relevant or fairly relevant issue, in the LEs subsample the distribution of frequencies is quite different: on the one hand, more than $30 \%$ of LEs have considered as non-relevant issue, whilst only $19 \%$ have judged to be absolutely relevant. Again, if considering the Lack of technical skills barrier, in SEs all enterprises have considered it to be at least a relevant issue, with values almost equally distributed across scores 3, 4 and 5; nonetheless, when looking at LEs, only 13\% of them have declared it to be an absolutely relevant issue, whilst about one third have considered it as fairly relevant. 
For what concerns the access to capital, as shown in recent studies on barriers to energy efficiency, SEs have greater difficulty accessing the same credit as LEs (Trianni \& Cagno 2012). This has been confirmed also by the analysis of frequencies, where half of the SEs considered access to capital as an absolutely relevant issue, compared with only a 13\% of LEs. Although this is beyond the scope of our analysis, it highlights the need to develop specific programmes for reducing the distance between SMEs (and in particular very small enterprises) and the institutions that provide them with the credit.

When looking at existing correlations between the barriers with respect to the firm's size (Table VII), some considerations can be drawn considering Medium Enterprises, since it is the most populated subsample (34 enterprises), as reported in Table III. Due to the reduction of the sample size, we have decided to adopt a higher correlation coefficient, equal to 0.7 (those criteria, i.e. at least 30 enterprises with correlation coefficients threshold at 0.7 , will be adopted also for the following correlation analyses of barriers with respect to the alloy, audit and country). Although this greater threshold value, we can see the correlation (0.74) between the uncertainty regarding the company’s future (Q6) and the issues of accessing the capital (Q23), whilst was not evident for the whole sample. Unfortunately, quite often for MEs but even truer for SMEs, accessing the credit is hindered by financial institutions that, especially in this situation of global financial crisis, tend to provide capital on the basis of the financial situation of an enterprise, rather than on the possible profitability of a project. This, coupled with the existing difficulties by financial institutions in evaluating energyefficient investment projects, leads to a very relevant limitation of the capital provided to energy-efficient investments, due to a difficult quantification and comprehension of the indirect benefits. For a thorough discussion of this topic, interesting contributions can be found, e.g. in Worrell et al. (Worrell et al. 2003), Pye and McKane (Pye \& Mckane 2000) and Mills and Rosenfelds (Mills \& Rosenfelds 1996) . 
Moreover, as emerged previously analysing the whole sample, conflicts of interest within the company (Q1) are correlated (0.71) with the lack of influence by the energy manager (Q5), expressing clearly how the Power barrier may affect enterprises. The correlations between the lack of influence of the energy manager (Q5) and a low priority given to energy management (Q8), and between the lack of budget funding (q17) and access to capital (q23), have not been pointed out as relevant although similar values, due to the increased threshold adopted.

Table VII. Perceived barriers - Medium Enterprises - Analysis of correlations

\subsection{Barriers by alloy}

When considering the main alloy produced by the investigated foundries, as shown in Table IV, it can be seen that the sample is not homogeneous. In fact, about half of the enterprises say they are focused on the production of cast iron, less than $25 \%$ on the production of cast steel, less than $25 \%$ aluminium, and only $4 \%$ (3 enterprises) on the production of copper. With such a limited number of enterprises in the copper subsample, it therefore seems reasonable to avoid drawing any conclusions, thus limiting the analyses to the other subsamples (i.e. cast iron, cast steel and aluminium).

Looking at the results (Table VIII), with a difference in the scores of at least 0.5, the enterprises devoted to the production of cast iron seem to suffer more from several of the barriers. This is the case with the questions related to the energy manager's lack of influence (with a score of 3.79 compared to 3.21 and 3.13 respectively for the enterprises producing cast steel and aluminium), the appropriateness of the technology (3.42 as opposed to 2.86 and 2.93 for cast steel and aluminium, respectively). 
Indeed, as reported by the analysis of frequencies (Figure 2), if about $70 \%$ of the Cast Iron enterprises have judged the lack of influence by the energy manager as an at least quite relevant issue, this share decreases to $50 \%$ and $47 \%$ respectively for Cast Steel and Aluminium enterprises. In addition to that, only 6\% of Cast Iron enterprises consider this issue as not relevant, compared with a share of $13 \%$ and even $21 \%$ respectively for Aluminium and Cast Steel ones.

Moreover, the analysis of frequencies is really interesting for the question about the appropriateness of the technology (Q12): about 12\% of Cast Iron enterprises provided low scores to this question, evaluating it as a not or fairly relevant issue. When analysing Cast Steel and Aluminium enterprises, this percentage is more than double (28\% and $27 \%$ respectively).

Figure 2. Perceived barriers - by Alloy -frequency of responses

There are also other cases in which the Cast Iron subsample shows relevant differences with respect to the Cast Steel subsample. This is the case with the questions related to the low priority of energy management (3.45 and 2.93), and the technical risks such as risk of production disruption (3.73 and 3.21).

As from the analysis of frequencies, the low priority of energy management is judged as a not or fairly relevant issue by only $12 \%$ of Cast Iron enterprises, in comparison with 
$43 \%$ of Cast Steel ones. Similarly, only $12 \%$ of the Cast Iron enterprises considered technical risks as a not or fairly relevant issue, compared with $21 \%$ of Cast Steel ones.

In addition to that, we can note that Aluminium enterprises, although from the sample composition tend to be of smaller size when compared to Cast Iron and Cast Steel enterprises, although not much evident, present lower barriers. Since this analysis does not confirm the analysis by firm's size, it points out that the Alloy factor alone might be relevant in modifying the perception of barriers to energy efficiency. Taking into consideration the results described above, it can be preliminarily concluded that foundries usually characterized by simpler production processes tend to have a greater perception of the barriers to the adoption of energy-efficient technologies. This might be explained by the fact that it is reasonable to assume that enterprises characterized by more complex production systems have already moved towards energy-efficient production and therefore do not seem to feel such burdensome barriers. Another contribution to the explanation might be that enterprises characterized by simpler production processes are now facing growing competition from emerging economies, which necessarily have lower labour costs (compared to the European ones), and thus are able to offer the market similar products at much lower prices. As a consequence, this lack of competitiveness is driving the attention of European enterprises towards energy efficiency, since it is recognized as a primary path for their survival. Yet a third reason for this may be that foundries with more a simple production process have less technical staff around who can work with technical energy efficiency improvement measures. Consequently, these foundries perceive barriers as greater than foundries with a higher degree of technical staff in their organisation.

Table IX. Perceived barriers - Cast Iron Enterprises - Analysis of correlations 
When looking at the correlations for the largest subsample (Cast Iron enterprises) reported in Table IX, we can find a relevant relationship of Lack of budget funding (Q17) and Access to Capital (Q23) (with a correlation coefficient equal to 0.78), as described above. Moreover, it is interesting to note the correlation between Low priority given to energy management (Q8) and Lack of staff awareness (Q10).

This result seems to suggest that if the staff has a clear perception that energy management is downgraded as a peripheral issue by the top management, the attention toward energy efficiency practices (expressed as awareness) becomes a greater barrier.

With respect to the sample composition, as described in Section 3, we can note that Cast Iron enterprises are larger, whilst Aluminium enterprises are smaller: since LEs tend to perceive lower barriers with respect to SEs, whilst Cast Iron enterprises tend to perceive greater barriers than the Aluminium ones, we might say that, at least from this preliminary analysis, the two factors (size and alloy) might be considered separately.

\subsection{Barriers by previous experience of energy audits}

A very interesting result can be observed when analysing the enterprises according to their previous experience of energy audits. The enterprises were asked whether they had conducted an energy audit before. As shown in Table X, we can see a relevant difference between enterprises that have performed an energy audit as opposed to those that have not in 20 out of 23 questions. Nonetheless, looking at the three remaining questions, the results are absolutely comparable (with very slight differences). Moreover, in three cases the difference between the scores in the two subsamples is greater than 0.5: this occurs for the questions related to conflicts of interest within the 
company, technical risks such as risk of production disruptions, and slim organization. Furthermore, in seven other cases the differences are greater than 0.3.

Table X. Perceived barriers - by energy audit

As reported in Figure 3, the analysis of frequencies shows interesting differences. Indeed, $43 \%$ of enterprises that had not conducted an energy audit, declared the conflicts of interest as a not relevant issue, compared with $18 \%$ that did an energy audit before. Moreover, the production disruption is feared as an absolutely relevant issue by only $7 \%$ of enterprises that have not performed an energy audit; when considering the other subsample, this percentage becomes 4 times bigger (29\%). Similarly for the Slim organization barrier, which has been judged as quite or absolutely relevant issue by only $26 \%$ of non-energy audit enterprises, compared with 56\% of enterprises that already experienced an energy audit.

Figure 3. Perceived barriers - by energy audit -frequency of responses

An overall conclusion from this analysis could be represented by the fact that having conducted an energy audit before caused several issues to emerge, making the enterprises more aware of the possible difficulties that can arise when undertaking the process of investing in energy-efficient technologies. This result is quite new with respect to previous research (Schleich 2004), for which energy audits was shown to reduce barriers to energy efficiency. The difference can be easily explained considering that the samples are quite different. Schleich has analysed services and small industry, thus investigating in relevant portion non-energy intensive activities, whilst in our 
study, we have been studying an energy intensive sector with a non-negligible share of large enterprises. Therefore, starting from the overall finding that this sample declare high barriers of lack of time and other priorities, an energy audit is a clear and undisputed marker of what enterprises do not implement, but should. Indeed, without an energy audit it is reasonable to assume that the enterprises will tend to underestimate the difficulties, thus showing a lower perception of the barriers, because they are not able to see the implications related to trying to remove the barriers. In fact, it is interesting to note that two out of three of the barriers with very different scores for the two subsamples (i.e. with a difference greater than 0.5 ) are related to the organization: enterprises that have performed energy audits show a greater perception of the difficulties in settling the conflicts of interest within the company, and of the slim organization that thus tends to inhibit the adoption of energy-efficient technology.

Analysing the correlations between barriers for the 38 enterprises that had already performed an energy audit (Table XI) we can observe few interesting relationships. Firstly, we have a confirmation of the relationship already emerged for the whole sample between Energy manager lack influence (Q5) with Low priority given to energy management (Q8), with a correlation coefficient of 0.70. Moreover, at correlation coefficient respectively equal to 0.76 and 0.71 we can find the barriers Lack of time and other priorities (Q13) with Slim organization (Q18), and Lack of technical skills (Q15) with poor information quality regarding energy efficiency opportunities (Q16). In the first case, it is reasonable people working in an enterprise with a slim organization will find even more difficult to find the time to look at energy consumption and/or to energy efficiency opportunities. In the second case, as suggested by Trianni and Cagno (Trianni \& Cagno 2012), we are likely to find a causal relationship: indeed, people without the needed technical skills to evaluate an energy-efficient technology will tend to perceive 
the available information as not sufficient to take decisions, thus highlighting the lower information quality about energy efficiency opportunities.

Table XI. Perceived barriers - Enterprises that have previously conducted an energy audit - Analysis of correlations

\subsection{Barriers by country}

In this study we have analysed the barriers with respect to the countries in which the enterprises operate. Looking at the enterprises located in Sweden, Germany (with 20 and 16 enterprises respectively, as shown in Table III), that together constitute more than $50 \%$ of the sample, we can observe several deviations from the average values for the whole sample (respectively in Table XII) and thus note several interesting considerations, also considering the frequency of responses reported in Figure 4.

Table XII. Perceived barriers - by Countries

Figure 4. Perceived barriers - by Countries - frequency of responses

First of all, considering German enterprises, we can observe generally lower values with respect to the corresponding average values, but only in one case with a difference greater than 0.5 (for the question about access to capital). In 5 other cases the difference is around 0.3 . It is interesting to note that in 3 out of 5 cases the barriers are related to 
technical-economic evaluations of energy efficiency, i.e. lack of sub-metering, technical risks such as risk of production disruptions, the cost of identifying opportunities, and analysing cost effectiveness and tendering.

In particular, only about $6 \%$ of German enterprises considered that lack of sub-metering was an absolutely relevant issue, compared with an average frequency of $23 \%$ for the whole sample. Even more interestingly we can see that none of German enterprises considered the technical risks as an absolutely relevant issue: when looking to that whole sample this share raises to $20 \%$. Finally, similar considerations can be drawn for the cost of identifying opportunities and analysing cost effectiveness and tendering, with none of the German enterprises considering it as an absolutely relevant issue, compared with $14 \%$ of the whole sample.

The same cannot be said for the Swedish enterprises, which, in this case, in 22 out of 23 questions show higher values than the average. In 6 cases, the difference against the average values for the barriers is greater than 0.5 , and in another 5 cases the difference is greater than 0.3. A possible explanation for this can be found in the historically lower energy prices - and, in particular, electricity prices - in Sweden compared to other European countries together with the highest share of electricity use among a number of studied European countries foundry industry’s (Rohdin et al., 2007). . Therefore, with the recent increases in energy prices, energy expenditures are becoming more relevant than in the past. Swedish enterprises may therefore be reflecting their worries and difficulties with respect to energy efficiency.

It is particularly important to note the scores for conflicts of interest within the company (3.6), the difficulties in accessing capital (4.25), and the lack of technical skills (4.15), with a distance from the average values of $0.77,0.6$ and 0.66 , respectively. 
In this regard, $55 \%$ of Swedish enterprises considered the access to capital as an absolutely relevant issue, compared with an average frequency of $28 \%$. Moreover, the lack of technical skills is considered as a relevant issue by $95 \%$ of the enterprises, compared with a frequency for the whole sample of about $80 \%$. The relevance of this result is even enlarged when considering that $85 \%$ of Swedish enterprises evaluated the lack of technical skills as a quite or absolutely relevant issue, compared with $59 \%$ for the whole sample.

With respect to the sample composition, as described in Section 3, we can note that, in the sample, German enterprises are generally medium-large, whilst the Swedish are smaller. Thus, at first attempt, it is not possible to attribute the difference between German and Swedish enterprises with respect to the whole sample to the country, rather on the firm's size. Nonetheless, always from the sample composition, when looking at the country with respect to the audit factors, and remembering that having performed an audit leads to an increased perception of barriers to energy-efficient technologies, we can note again a difference between German and Swedish enterprises. Indeed, in both countries the number of enterprises that have performed an audit is large (respectively 75\% and 70\%). Nonetheless, since German enterprises present lower barriers with respect to the whole sample, whilst Swedish ones have greater barriers, the effect of the country seems apparent. It seems important to note that this consideration can be drawn since the sample is homogeneous when looking at firm's size and audit factors combined.

\section{Conclusions}

This study has dealt with barriers to energy efficiency, i.e. a topic widely investigated in 
the literature, but, at the moment, still with few empirical studies providing field investigations that could really help support policy-makers in understanding the firm's characteristics that might affect barriers and thus promoting the most effective policies to secure widespread adoption of energy-efficient technologies and practices. For this reason, we have performed, through semi-structured interviews supported by a questionnaire, a preliminary insight into barriers to energy efficiency in European foundries, a sector that, in terms of energy consumption, number of employees, number of enterprises plays a strategic role for the European economy.

With respect to previous studies, the aim was to highlight the existence, in some cases, of more than one theoretical barrier with respect to operational ones that can limit investments in energy-efficient technologies. This is relevant since without a clear comprehension of the effective barriers affecting an enterprise any policy would be abruptly ineffective.

Looking at the results, the study has pointed out a general lack of resources in terms of time and capital and the need to guarantee the continuity of the business, thus fearing possible hidden costs related to production hassle or disruption, and the technical risks.

This preliminary result should be carefully considered by future policy-makers, making clear the need on the one hand to provide capital support to enterprises, but, on the other hand, to try to point out the possible hidden costs related to an investment in energyefficient technologies, in order to avoid promoting interventions that might deeply affect enterprises' business continuity. The analysis has also shown that barriers related to the internal organization are not generally perceived as a major issue: this is reasonably due to the status quo of enterprises hit by the financial and economic crisis.

Nonetheless, by considering the factors that might affect the perception of barriers 
towards the adoption of energy-efficient technologies, this preliminary insight into European foundries has shown that the picture is far to be homogeneous.

Indeed, by looking at firm's size, we could appreciate substantial differences between SEs and LEs, and even within SMEs, confirming other another recent study (Trianni \& Cagno 2012) that highlights how barriers perceived by SMEs may differ significantly. Again, although this result should be taken with caution and within the limitation of the study, it seems on the one hand to make a recommendation to policy-makers to account for this difference when enacting policies to promote industrial energy efficiency, on the other hand, it offers an important contribution to the academic literature, which, as now, has treated SMEs, with respect to the barriers to energy efficiency, as a homogenous group, which is not correct. In particular, several differences can be identified in an organizational perspective, with small enterprises suffering for example a lack of specific personnel dedicated to researching energy efficiency and opportunities, calling for future research in this field. In particular, we can see two paths: firstly, it seems that only enlarging the sample analysed will allow to make more steady conclusions; secondly, it is quite interesting to understand, according to the different firm's size, which are the most effective means that may promote energy efficiency within foundries.

As regards the analysis of the sample by alloy, it is possible to observe that, in this preliminary analysis, foundries with simpler production processes present a greater perception of the barriers. This could be related to the fact that enterprises characterized by more complex processes might require a more strict control of the operations, thus moving towards practices for energy management. Nonetheless, since the sample is limited and not representative of the whole population of foundries, future research on this topic might explore more deeply the differences in the technologies adopted and try 
to perform an analysis of the barriers according to process-specific energy-efficient technologies. In addition to that, since the study has been conducted investigating barriers to energy efficiency in general, it seems important to extend the investigation to the barriers hindering the adoption to technologies specifically developed for foundries.

A factor that could be deeper explored by future research, since it has shown to have a relevant impact on barriers to energy efficiency, is the energy audit. Already investigated in other sectors (Schleich 2004), in the present research enterprises that had already performed an energy audit reported a diffused higher perception of barriers. In fact, having conducted an energy audit may have increased the awareness of enterprises with respect to the effective difficulties incurring when undertaking an investment in energy-efficient technologies. Indeed, once inefficiencies have been pointed out, as well as opportunities to reduce energy consumption, it seems that respondents can see more clearly what should be done, thus facing neatly the effective barriers to the implementation. This factor seems of great importance both for enterprises and policymakers, since future energy policies towards energy efficiency necessarily need to increase the enterprises' awareness towards this topic. Therefore, only with a diffused campaign of energy audits and investigation of barriers will it be possible to increase awareness of energy efficiency and spread the necessary knowledge to secure the adoption of energy-efficient technologies. Nonetheless, since in other contexts the role of energy audits have shown to be different, future research could enlarge the investigation in order to reach higher levels of confidence of the results.

The analysis by country, whenever possible due to the limited sample, has shown a quite relevant perception of barriers, showing clearly that Swedish foundries behave differently with respect to the total sample, with greater perceived barriers in almost all questions. Conversely, interesting insights might come from deeper analysis of the 
difference with German foundries that, in this study, showed much lower barriers. Therefore, these preliminary findings stimulate future research, on the one hand to enlarge the sample investigated; on the other hand trying, through a detailed analysis of the domestic context in which foundries operate, to link the perception of barriers to energy-efficient technologies to the domestic energy policies in place. Indeed, this opportunity for future research might reveal the most effective drivers to promote the adoption of energy efficiency interventions at European level.

\section{Acknowledgments}

The study has been carried out under the FoundryBench project financed by the European Commission within Intelligent Energy Europe. We kindly thank Lorenzo Giudici for his valuable contribution to this work. The authors also warmly thank the respondents at the studied foundries for giving freely of their time and attention to answer the questions, and three anonymous reviewers for their relevant inputs and constructive suggestions.

\section{References}

Brown, M.A., 2001. Market failures and barriers as a basis for clean energy policies. Energy Policy, 29, pp.1197-1207.

Cagno, E. et al., 2010. Quick-E-scan: A methodology for the energy scan of SMEs. Energy, 35(5), pp.1916-1926.

DeCanio, S.J., 1993. Barriers within firms to energy- efficient investments. Energy Policy, pp.906-914.

DeCanio, S.J., 1998. The efficiency paradox : bureaucratic and organizational barriers to profitable energy-saving investments. energy policy, 26(5), pp.441-454.

Energy Information Administration, 2010. International Energy Outlook, Washington, DC, US. 
Energy Information Administration, 2011. International Energy Outlook 2011, Washington: US Department of Energy - Energy Information Administration.

European Commission, 2011. COM(2011)370 final, Proposal for a Directive of the European Parliament and of the Council on Energy Efficiency and repealing Directives 2004/8/EC and 2006/32/EC.

European Council, 2003. Commission Recommendation of 6 May 2003 concerning the definition of micro, small and medium-sized enterprises. , p.6.

European Council, 2009. Directive 2009/28/EC of the European Parliament and of the Council of 23 April 2009 on the promotion of the use of energy from renewable sources and amending and subsequently repealing Directives 2001/77/EC and 2003/30/EC, pp.16-62.

Eurostat, 2011. Europe in figures - Eurostat yearbook 2011 European Commission, ed., Luxembourg: Publications Office of the European Union.

Fleiter, T., Worrell, E. \& Eichhammer, W., 2011. Barriers to energy efficiency in industrial bottom-up energy demand models-A review. Renewable and Sustainable Energy Reviews, 15(6), pp.3099-3111.

Golove, W.H. \& Eto, J.H., 1996. Market Barriers to Energy Efficiency: A Critical Reappraisal of the Rationale for Public Policies to Promote Energy Efficiency. Energy \& Environment, (March).

de Groot, F.H.L., Verhoef, E.T. \& Nijkamp, P., 2001. Energy saving by firms : decision-making , barriers and policies. Energy Economics, 23(6), pp.717-740.

Gruber, E.; Brand, M. (1991): Promoting energy conservation in small and mediumsized companies. Energy Policy, 19 (3), pp. 279-287.

Hewett, M.J., 1998. Achieving energy efficiency in a restructured electric utility industry, Minneapolis, MN, US.

Hirst, E. \& Brown, M., 1990. Closing the efficiency gap : barriers to the efficient use of energy. Resources, Conservation and Recycling, 3, pp.267-281.

Howarth, R.B. \& Andersson, B., 1993. Market barriers to energy efficiency. Energy Economics, pp.262-272.

IEA/OECD, 2009. World Energy Outlook, Paris, France.

IPCC, 2001. Third Assessment Report: Barriers, Opportunities, and Market Potential of Technologies and Practices. In Third Assessment Report. Cambridge, UK: Cambridge University Press, p. 54.

Jaffe, A.B. \& Stavins, R.N., 1994. The energy-efficiency gap What does it mean? Energy Policy, 22(10), pp.804-810. 
Koomey, J.G. \& Sanstad, A.H., 1994. Technical evidence for assessing the performance of markets affecting energy efficiency. Energy Policy, 22(10), pp.826-832.

Mills, E. \& Rosenfelds, A.R.T., 1996. CONSUMER NON-ENERGY BENEFITS MAKING ENERGY-EFFICIENCY AS A MOTIVATION IMPROVEMENTS FOR. Energy, 21(718), pp.5-9.

Nichols, A.L., 2000. Demand-side management Overcoming market barriers or obscuring real costs ? Energy Policy, 22(10), pp.840-847.

Palm, J. \& Thollander, P., 2010. An interdisciplinary perspective on industrial energy efficiency. Applied Energy, 87(10), pp.3255-3261.

Patterson, M.G., 1996. What is energy efficiency? Concepts, indicators and methodological issues. , 24(5), pp.377-390.

Patton, M.Q., 1991. Qualitative Research \& Evaluation Methods Third Edit., Saint Paul, MN, US: Sage Publication, Inc.

Pye, M. \& Mckane, A., 2000. Making a stronger case for industrial energy efficiency by quantifying non-energy benefits. Resources, Conservation And Recycling, 28, pp.171-183.

Reddy, A.K.N., 1991. Barriers to improvements in energy efficiency. Energy Policy, 19(10), pp.953-961.

Rohdin, P. \& Thollander, P., 2006. Barriers to and driving forces for energy efficiency in the non-energy intensive manufacturing industry in Sweden. Energy, 31(12), pp.1836-1844.

Rohdin, P., Thollander, P. \& Solding, P., 2007. Barriers to and drivers for energy efficiency in the Swedish foundry industry. Energy Policy, 35(1), pp.672-677.

Russell, B.H., 1988. Research Methods in Cultural Anthropology, Newbury Park, Ca, US: Sage Publication, Inc.

Sanstad, Alan H \& Howarth, R.B., 1994. 'Normal ' markets , market imperfections and energy efficiency. Energy Policy, 22(10), pp.811-818.

Sanstad, Alan H, Koomey, Jonathan G \& Levine, M.D., 1993. On the economic analysis of problems in energy efficiency Market barriers, market failures, and policy implications, Berkeley, CA, US.

Sardianou, E., 2008. Barriers to industrial energy efficiency investments in Greece. Journal of Cleaner Production, 16(13), pp.1416-1423.

Schleich, J., 2009. Barriers to energy efficiency: A comparison across the German commercial and services sector. Ecological Economics, 68(7), pp.2150-2159.

Schleich, J., 2004. Do energy audits help reduce barriers to energy efficiency? An empirical analysis for Germany. , 2(3), pp.226-239. 
Schleich, J. \& Gruber, E., 2008. Beyond case studies: Barriers to energy efficiency in commerce and the services sector. Energy Economics, 30(2), pp.449-464.

Shipley, A.M. and Elliot, R.E. Energy efficiency programs for small and medium sized industry. In: Proceedings of the 2001 ACEEE summer study on energy efficiency in industry, vol. 1; 2001. p. 183-96.

Sorrell, S. et al., 2000. Reducing barriers to energy efficiency in public and private organisations, SPRU, Final Report, 2000. Available at: http://www.sussex.ac.uk/Units/spru/publications/reports/barriers/final.html.

Sorrell, S. et al., 2004. The economics of Energy Efficiency, Cheltenham, UK: Edward Elgar Publishing.

Sorrell, S., Mallett, A. \& Nye, S., 2010. Barriers to industrial energy efficiency : a literature review, background study for the UNIDO Industrial Development Report (IDR) 'Industrial energy efficiency pays, why is it not happening? Brighton: SPRU, University of Sussex; 2010.

Stern, P.C. \& Aronson, E., 1984. Energy use: the human dimension Stern, ed., New York, NY, US: W.H. Freeman.

Sutherland, R.J., 1996. The economics of energy conservation policy. Energy Policy, 24(4), pp.361-370.

Thollander, P., Danestig, M. \& Rohdin, P., 2007. Energy policies for increased industrial energy efficiency: Evaluation of a local energy programme for manufacturing SMEs. Energy Policy, 35(11), pp.5774-5783.

Thollander, P. \& Ottosson, M., 2008. An energy efficient Swedish pulp and paper industry - exploring barriers to and driving forces for cost-effective energy efficiency investments. Energy Efficiency, 1(1), pp.21-34.

Thollander, P. \& Ottosson, M., 2010. Energy management practices in Swedish energyintensive industries. Journal of Cleaner Production, 18(12), pp.1125-1133.

Trianni, A. \& Cagno, E., 2012. Dealing with barriers to energy efficiency and SMEs: Some empirical evidences. Energy, 37(1), pp.494-504.

Velthuijsen, J.W., 1995. Determinants of Investment in Energy Conservation. Foundation for Economic Research of the University of Amsterdam.

Velthuijsen, J.W., 1993. Incentives for investment in energy efficiency: an econometric evaluation and policy implications. Environmental \& Resource Economics, 3(2), pp.153-169.

Worrell, E. et al., 2010. Energy Efficiency Improvement and Cost Saving Opportunities for the U.S. Iron and Steel Industry An ENERGY STAR ${ }^{\circledR}$ Guide for Energy and Plant Managers, Berkeley, CA, US. 
Worrell, E. et al., 1997. Energy intensity in the iron and steel industry: a comparison of physical and economic indicators. Energy Policy, 25(7-9), pp.727-744.

Worrell, E. \& Biermans, G., 2005. Move over! Stock turnover, retrofit and industrial energy efficiency. Energy Policy, 33(7), pp.949-962.

Worrell, Ernst, 1995. Advanced technologies and energy efficiency in the iron and steel industry in China. Energy for Sustainable Development, 2(4), pp.27-40.

Worrell, Ernst et al., 2003. Productivity benefits of industrial energy efficiency measures. Energy, 28, pp.1081-1098.

Yin, R.K., 2003. Case Study Research: Design and Methods , 3rd Edition, Thousand Oaks: Sage Publication, Inc.

Zhang, J. \& Wang, G., 2008. Energy saving technologies and productive efficiency in the Chinese iron and steel sector. Energy, 33, pp.525-537. 


\section{List of Tables}

Table I. Barriers to energy efficiency: the Sorrell et al. taxonomy (Sorrell et al., 2000).

\begin{tabular}{|c|c|c|}
\hline $\begin{array}{l}\text { Theoretical } \\
\text { Framework }\end{array}$ & $\begin{array}{l}\text { Theoretical } \\
\text { barrier }\end{array}$ & Comment \\
\hline \multirow{4}{*}{$\begin{array}{l}\text { Economic non- } \\
\text { market failure }\end{array}$} & Heterogeneity & A technology or measure may be cost-efficient in general, but not in all cases. \\
\hline & Hidden costs & $\begin{array}{l}\text { Examples of hidden costs are overhead costs, cost of collecting and analysing } \\
\text { information, production disruptions, inconvenience, etc. }\end{array}$ \\
\hline & Access to capital & $\begin{array}{l}\text { Limited access to capital may prevent energy efficiency measures from being } \\
\text { implemented. }\end{array}$ \\
\hline & Risk & $\begin{array}{l}\text { Risk aversion may be the reason why energy efficiency measures are } \\
\text { constrained by short pay-back criteria. }\end{array}$ \\
\hline \multirow[t]{4}{*}{$\begin{array}{l}\text { Economic } \\
\text { market failure }\end{array}$} & $\begin{array}{l}\text { Imperfect } \\
\text { Information }\end{array}$ & $\begin{array}{l}\text { Lack of information may lead to cost-effective energy efficiency opportunities } \\
\text { being missed. }\end{array}$ \\
\hline & Split incentives & $\begin{array}{l}\text { If a person or department cannot gain from energy efficiency investments it is } \\
\text { likely that implementation will be of less interest. }\end{array}$ \\
\hline & Adverse selection & $\begin{array}{l}\text { If suppliers know more about the energy performance of goods than } \\
\text { purchasers, the purchasers may select goods on the basis of visible aspects such } \\
\text { as price. }\end{array}$ \\
\hline & $\begin{array}{l}\text { Principal-agent } \\
\text { relationships }\end{array}$ & $\begin{array}{l}\text { Strict monitoring and control by the principal, since he or she cannot see that } \\
\text { what the agent is doing, may result in energy efficiency measures being ignored. }\end{array}$ \\
\hline \multirow[t]{5}{*}{ Behavioural } & $\begin{array}{l}\text { Bounded } \\
\text { rationality }\end{array}$ & $\begin{array}{l}\text { Instead of being based on perfect information, decisions are made by rule of } \\
\text { thumb. }\end{array}$ \\
\hline & $\begin{array}{l}\text { Form of } \\
\text { information }\end{array}$ & $\begin{array}{l}\text { Research has shown that the form of information is critical. Information should } \\
\text { be specific, vivid, simple, and personal to increase its chances of being accepted. }\end{array}$ \\
\hline & $\begin{array}{l}\text { Credibility and } \\
\text { trust }\end{array}$ & $\begin{array}{l}\text { The information source should be credible and trustworthy in order to } \\
\text { successfully deliver information regarding energy efficiency measures. If these } \\
\text { factors are lacking this will result in inefficient choices. }\end{array}$ \\
\hline & Inertia & $\begin{array}{l}\text { Individuals who are opponents to change within an organization may result in } \\
\text { overlooking energy efficiency measures that are cost-efficient. }\end{array}$ \\
\hline & Values & $\begin{array}{l}\text { Efficiency improvements are most likely to be successful if there are individuals } \\
\text { with real ambition, preferably represented by a key individual within the top } \\
\text { management. }\end{array}$ \\
\hline \multirow[t]{2}{*}{ Organizational } & Power & $\begin{array}{l}\text { Low status of energy management may lead to lower priority of energy issues } \\
\text { within organizations. }\end{array}$ \\
\hline & Culture & $\begin{array}{l}\text { Organizations may encourage energy efficiency investments by developing a } \\
\text { culture characterized by environmental values. }\end{array}$ \\
\hline
\end{tabular}


Table II. Operational difficulties and theoretical barriers according to Sorrell et al. (Sorrell et al., 2000).

\begin{tabular}{lll}
\hline & Operational difficulty & Theoretical barriers \\
\hline Q1 & Conflicts of interest within the company & Power \\
Q2 & Long decision chains & Power \\
Q3 & Cost of staff replacement/retirement/retraining & Hidden Costs \\
Q4 & Department or workers not accountable for energy costs & Split Incentives \\
Q5 & Energy manager lacks influence & Power \\
Q6 & Uncertainty regarding the company's future & Risk \\
Q7 & Cost of production disruption/hassle/inconvenience & Hidden Costs \\
Q8 & Low priority given to energy management & Power \\
Q9 & Lack of sub-metering & Imperfect Information \\
Q10 & Lack of staff awareness & Values, Culture \\
Q11 & Energy objectives not integrated into & Power \\
& operating/maintenance or purchasing procedures & \\
Q12 & Technology is inappropriate at this site & Heterogeneity \\
Q13 & Lack of time or other priorities & Hidden Costs, Power, Values \& Culture \\
Q14 & Technical risks such as risk of production disruptions & Risk, Hidden Costs \\
Q15 & Lack of technical skills & Hidden Costs, Bounded Rationality \\
Q16 & Poor information quality regarding energy efficiency & Form of Information, Imperfect Information \\
& opportunities & \\
Q17 & Lack of budget funding & Power, Access to Capital \\
Q18 & Slim organization & Power \\
Q19 & Difficulties in obtaining information about the energy & Hidden Costs \\
& consumption of purchased equipment & \\
Q20 & Cost of identifying opportunities/analysing cost & Hidden Costs \\
& effectiveness and tendering & \\
Q21 & Possible poor performance of equipment & Heterogeneity, Risk \\
Q22 & Other priorities for capital investments & Values \& Culture, Power \\
Q23 & Access to capital & Access to Capital \\
\hline
\end{tabular}


Table III. Description of the sample by Firm's size vs Alloy, Audit and Country.

\begin{tabular}{|c|c|c|c|c|c|c|c|c|c|c|c|c|c|c|}
\hline \multirow[b]{2}{*}{ by size } & \multirow[b]{2}{*}{ Total } & \multicolumn{4}{|c|}{ Alloy } & \multicolumn{2}{|c|}{ Audit } & \multicolumn{7}{|c|}{ Country } \\
\hline & & Cast Iron & Cast Steel & Copper & Aluminium & No & Yes & $\mathrm{FI}$ & $F R$ & $G E$ & IT & $P O$ & $S P$ & SW \\
\hline SEs & 15 & 6 & 1 & 0 & 8 & 7 & 8 & 2 & 2 & 0 & 1 & 1 & 1 & 8 \\
\hline MEs & 34 & 17 & 9 & 3 & 5 & 14 & 20 & 1 & 6 & 8 & 1 & 2 & 4 & 12 \\
\hline LEs & 16 & 10 & 4 & 0 & 2 & 6 & 10 & 1 & 2 & 8 & 2 & 3 & 0 & 0 \\
\hline \multirow[t]{11}{*}{ Total } & 65 & 33 & 14 & 3 & 15 & 27 & 38 & 4 & 10 & 16 & 4 & 6 & 5 & 20 \\
\hline & & & \multicolumn{2}{|c|}{ by Alloy } & Total & No & Yes & $\mathrm{FI}$ & $F R$ & $G E$ & IT & $P O$ & $S P$ & $S W$ \\
\hline & & & \multirow{5}{*}{\multicolumn{2}{|c|}{$\begin{array}{l}\text { Cast Iron } \\
\text { Cast Steel } \\
\text { Copper } \\
\text { Aluminium } \\
\text { Total }\end{array}$}} & 33 & 13 & 20 & 0 & 5 & 12 & 2 & 3 & 2 & 3 \\
\hline & & & & & 14 & 8 & 6 & 1 & 2 & 2 & 1 & 1 & 3 & 4 \\
\hline & & & & & 3 & 0 & 3 & 1 & 0 & 0 & 0 & 0 & 0 & 2 \\
\hline & & & & & 15 & 6 & 9 & 2 & 3 & 2 & 1 & 2 & 0 & 5 \\
\hline & & & & & 65 & 27 & 38 & 4 & 10 & 16 & 4 & 6 & 5 & 14 \\
\hline & & & & & \multicolumn{2}{|c|}{ by Audit } & Total & $\mathrm{FI}$ & $F R$ & $G E$ & IT & $P O$ & $S P$ & SW \\
\hline & & & & & \multicolumn{2}{|c|}{ No } & 27 & 2 & 6 & 4 & 3 & 4 & 2 & 6 \\
\hline & & & & & \multicolumn{2}{|c|}{ Yes } & 38 & 2 & 4 & 12 & 1 & 2 & 3 & 14 \\
\hline & & & & & \multicolumn{2}{|c|}{ Total } & 65 & 4 & 10 & 16 & 4 & 6 & 5 & 20 \\
\hline
\end{tabular}


Table IV. Perceived barriers - total sample - average score and frequency of responses.

\begin{tabular}{|c|c|c|c|c|c|c|}
\hline Operational difficulty & Average Score & $\begin{array}{c}\text { Not } \\
\text { relevant }\end{array}$ & $\begin{array}{c}\text { Fairly } \\
\text { relevant }\end{array}$ & relevant & $\begin{array}{c}\text { Very } \\
\text { relevant }\end{array}$ & $\begin{array}{c}\text { Absolutely } \\
\text { relevant }\end{array}$ \\
\hline Conflicts of interest within the company & 2.83 & $28 \%$ & $8 \%$ & $25 \%$ & $32 \%$ & $8 \%$ \\
\hline Long decision chains & 2.88 & $20 \%$ & $23 \%$ & $20 \%$ & $23 \%$ & $14 \%$ \\
\hline Cost of staff replacement/retirement/retraining & 2.95 & $12 \%$ & $28 \%$ & $18 \%$ & $35 \%$ & $6 \%$ \\
\hline Department or workers not accountable for energy costs & 3.72 & $3 \%$ & $11 \%$ & $15 \%$ & $52 \%$ & $18 \%$ \\
\hline Energy manager lacks influence & 3.54 & $11 \%$ & $9 \%$ & $18 \%$ & $38 \%$ & $23 \%$ \\
\hline Uncertainty regarding the company's future & 3.14 & $18 \%$ & $17 \%$ & $15 \%$ & $31 \%$ & $18 \%$ \\
\hline Cost of production disruption/hassle/inconvenience & 3.69 & $5 \%$ & $12 \%$ & $11 \%$ & $54 \%$ & $18 \%$ \\
\hline Low priority given to energy management & 3.32 & $6 \%$ & $17 \%$ & $31 \%$ & $31 \%$ & $15 \%$ \\
\hline Lack of sub-metering & 3.51 & $11 \%$ & $12 \%$ & $12 \%$ & $42 \%$ & $23 \%$ \\
\hline Lack of staff awareness & 3.54 & $3 \%$ & $12 \%$ & $25 \%$ & $48 \%$ & $12 \%$ \\
\hline $\begin{array}{l}\text { Energy objectives not integrated into operating/maintenance or purchasing } \\
\text { procedures }\end{array}$ & 3.57 & $2 \%$ & $17 \%$ & $17 \%$ & $52 \%$ & $12 \%$ \\
\hline Technology is inappropriate at this site & 3.25 & $11 \%$ & $8 \%$ & $38 \%$ & $32 \%$ & $11 \%$ \\
\hline Lack of time or other priorities & 3.71 & $5 \%$ & $6 \%$ & $25 \%$ & $43 \%$ & $22 \%$ \\
\hline Technical risks such as risk of production disruptions & 3.66 & $3 \%$ & $11 \%$ & $23 \%$ & $43 \%$ & $20 \%$ \\
\hline Lack of technical skills & 3.49 & $6 \%$ & $14 \%$ & $22 \%$ & $42 \%$ & $17 \%$ \\
\hline Poor information quality regarding energy efficiency opportunities & 3.55 & $5 \%$ & $5 \%$ & $31 \%$ & $51 \%$ & $9 \%$ \\
\hline Lack of budget funding & 4.11 & $5 \%$ & $3 \%$ & $20 \%$ & $22 \%$ & $51 \%$ \\
\hline Slim organization & 3.42 & $8 \%$ & $8 \%$ & $40 \%$ & $25 \%$ & $20 \%$ \\
\hline $\begin{array}{l}\text { Difficulties in obtaining information about the energy consumption of purchased } \\
\text { equipment }\end{array}$ & 3.40 & $5 \%$ & $9 \%$ & $40 \%$ & $34 \%$ & $12 \%$ \\
\hline Cost of identifying opportunities/analysing cost effectiveness and tendering & 3.57 & $3 \%$ & $8 \%$ & $32 \%$ & $43 \%$ & $14 \%$ \\
\hline Possible poor performance of equipment & 3.37 & $5 \%$ & $17 \%$ & $29 \%$ & $35 \%$ & $14 \%$ \\
\hline Other priorities for capital investments & 3.89 & $0 \%$ & $11 \%$ & $17 \%$ & $45 \%$ & $28 \%$ \\
\hline Access to capital & 3.65 & $6 \%$ & $12 \%$ & $20 \%$ & $34 \%$ & $28 \%$ \\
\hline Average value & 3.47 & $8 \%$ & $12 \%$ & $24 \%$ & $39 \%$ & $18 \%$ \\
\hline
\end{tabular}


Table V. Perceived barriers - total sample - Analysis of correlations

\begin{tabular}{|c|c|c|c|c|c|c|c|c|c|c|c|c|c|c|c|c|c|c|c|c|c|c|c|}
\hline & Q1 & Q2 & Q3 & Q4 & Q5 & Q6 & Q7 & Q8 & Q9 & Q10 & Q11 & Q12 & Q13 & Q14 & Q15 & Q16 & Q17 & Q18 & Q19 & Q20 & Q21 & Q22 & Q.23 \\
\hline $\begin{array}{l}\mathrm{Q1} \\
\end{array}$ & $\overline{-1}$ & 0.42 & $\begin{array}{c}0.29 \\
\end{array}$ & $\begin{array}{l}0.32 \\
\end{array}$ & 0.61 & $\begin{array}{l}0.38 \\
\end{array}$ & 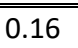 & $\begin{array}{l}0.47 \\
\end{array}$ & $\begin{array}{c}0.09 \\
\end{array}$ & $\begin{array}{c}0.28 \\
\end{array}$ & \begin{tabular}{c|}
0.24 \\
\end{tabular} & \begin{tabular}{c|c|}
0.35 \\
\end{tabular} & 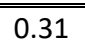 & \begin{tabular}{c|}
0.28 \\
\end{tabular} & 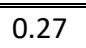 & 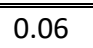 & $\begin{array}{c}0.26 \\
\end{array}$ & \begin{tabular}{c|c|c|}
0.29 \\
\end{tabular} & 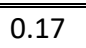 & 0 & 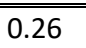 & 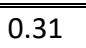 & $\begin{array}{l}0.40 \\
\end{array}$ \\
\hline Q2 & & - & 0.27 & 0.18 & 0.57 & 0.45 & 0.28 & 0.35 & 0.18 & 0.36 & 0.23 & 0.32 & 0.13 & 0.32 & 0.25 & 0.22 & 0.54 & 0.28 & 0.20 & 0.09 & 0.39 & 0.19 & 0.41 \\
\hline Q3 & & & - & 0.34 & 0.32 & 0.17 & 0.28 & 0.33 & -0.07 & 0.20 & 0.06 & 0.12 & 0.32 & 0.39 & 0.21 & 0.00 & 0.35 & 0.32 & 0.30 & 0.12 & 0.17 & 0.33 & 0.24 \\
\hline Q4 & & & & - & 0.17 & 0.26 & 0.44 & 0.21 & 0.19 & 0.37 & 0.38 & 0.32 & 0.26 & 0.29 & 0.28 & 0.19 & 0.27 & 0.45 & 0.55 & 0.16 & 0.29 & 0.17 & 0.21 \\
\hline Q5 & & & & & - & 0.52 & 0.15 & 0.65 & 0.12 & 0.38 & 0.35 & 0.46 & 0.25 & 0.39 & 0.28 & 0.23 & 0.59 & 0.26 & 0.10 & -0.03 & 0.37 & 0.38 & 0.51 \\
\hline Q6 & & & & & & - & 0.27 & 0.53 & 0.20 & 0.38 & 0.34 & 0.31 & 0.12 & 0.24 & 0.34 & 0.30 & 0.48 & 0.26 & 0.05 & 0.11 & 0.36 & 0.42 & 0.54 \\
\hline Q7 & & & & & & & - & 0.18 & 0.26 & 0.30 & 0.19 & 0.20 & 0.39 & 0.35 & 0.34 & 0.33 & 0.42 & 0.42 & 0.54 & 0.24 & 0.32 & 0.42 & 0.41 \\
\hline Q8 & & & & & & & & - & 0.17 & 0.50 & 0.48 & 0.34 & 0.41 & 0.28 & 0.54 & 0.30 & 0.40 & 0.36 & 0.21 & 0.27 & 0.29 & 0.26 & 0.54 \\
\hline Q9 & & & & & & & & & - & 0.33 & 0.23 & 0.39 & 0.13 & 0.24 & 0.26 & 0.32 & 0.29 & 0.23 & 0.29 & 0.46 & 0.42 & 0.19 & 0.37 \\
\hline Q10 & & & & & & & & & & - & 0.53 & 0.44 & 0.40 & 0.30 & 0.47 & 0.37 & 0.49 & 0.51 & 0.28 & 0.17 & 0.35 & 0.24 & 0.38 \\
\hline Q11 & & & & & & & & & & & - & 0.47 & 0.31 & 0.07 & 0.52 & 0.40 & 0.38 & 0.49 & 0.33 & 0.21 & 0.35 & 0.17 & 0.19 \\
\hline Q12 & & & & & & & & & & & & - & 0.35 & 0.27 & 0.43 & 0.47 & 0.37 & 0.42 & 0.44 & 0.15 & 0.54 & 0.22 & 0.34 \\
\hline Q13 & & & & & & & & & & & & & - & 0.31 & 0.33 & 0.33 & 0.50 & 0.50 & 0.40 & 0.24 & 0.31 & 0.45 & 0.39 \\
\hline Q14 & & & & & & & & & & & & & & - & 0.23 & 0.31 & 0.39 & 0.39 & 0.32 & 0.34 & 0.43 & 0.37 & 0.34 \\
\hline Q15 & & & & & & & & & & & & & & & - & 0.53 & 0.26 & 0.42 & 0.40 & 0.38 & 0.46 & 0.20 & 0.38 \\
\hline Q16 & & & & & & & & & & & & & & & & - & 0.31 & 0.32 & 0.33 & 0.44 & 0.58 & 0.07 & 0.27 \\
\hline Q17 & & & & & & & & & & & & & & & & & - & 0.45 & 0.24 & 0.10 & 0.38 & 0.44 & 0.60 \\
\hline Q18 & & & & & & & & & & & & & & & & & & - & 0.48 & 0.28 & 0.32 & 0.38 & 0.39 \\
\hline Q19 & & & & & & & & & & & & & & & & & & & - & 0.40 & 0.48 & 0.30 & 0.31 \\
\hline Q20 & & & & & & & & & & & & & & & & & & & & - & 0.35 & 0.04 & 0.25 \\
\hline Q21 & & & & & & & & & & & & & & & & & & & & & - & 0.27 & 0.39 \\
\hline Q22 & & & & & & & & & & & & & & & & & & & & & & - & 0.55 \\
\hline Q23 & & & & & & & & & & & & & & & & & & & & & & & - \\
\hline
\end{tabular}


Table VI. Perceived barriers - by firm's size

\begin{tabular}{|c|c|c|c|c|c|}
\hline & Operational difficulty & $\begin{array}{c}\text { Average } \\
\text { Score }\end{array}$ & SEs & MEs & LEs \\
\hline Q1 & Conflicts of interest within the company & 2.83 & 3.00 & 2.76 & 2.88 \\
\hline Q2 & Long decision chains & 2.88 & 2.71 & 3.00 & 2.81 \\
\hline Q3 & $\begin{array}{l}\text { Cost of staff } \\
\text { replacement/retirement/retraining }\end{array}$ & 2.95 & 2.79 & 3.24 & 2.56 \\
\hline Q4 & $\begin{array}{l}\text { Department or workers not accountable for } \\
\text { energy costs }\end{array}$ & 3.72 & 3.86 & 3.74 & 3.56 \\
\hline Q5 & Energy manager lacks influence & 3.54 & 3.43 & 3.62 & 3.56 \\
\hline Q6 & Uncertainty regarding the company's future & 3.14 & 2.86 & 3.26 & 3.19 \\
\hline Q7 & $\begin{array}{l}\text { Cost of production } \\
\text { disruption/hassle/inconvenience }\end{array}$ & 3.69 & 3.93 & 3.56 & 3.75 \\
\hline Q8 & Low priority given to energy management & 3.32 & 3.64 & 3.41 & 2.88 \\
\hline Q9 & Lack of sub-metering & 3.51 & 4.29 & 3.09 & 3.69 \\
\hline Q10 & Lack of staff awareness & 3.54 & 3.93 & 3.50 & 3.31 \\
\hline Q11 & $\begin{array}{l}\text { Energy objectives not integrated into } \\
\text { operating/maintenance or purchasing } \\
\text { procedures }\end{array}$ & 3.57 & 3.86 & 3.62 & 3.19 \\
\hline Q12 & Technology is inappropriate at this site & 3.25 & 3.43 & 3.09 & 3.44 \\
\hline Q13 & Lack of time or other priorities & 3.71 & 4.14 & 3.79 & 3.19 \\
\hline Q14 & $\begin{array}{l}\text { Technical risks such as risk of production } \\
\text { disruptions }\end{array}$ & 3.66 & 3.57 & 3.79 & 3.50 \\
\hline Q15 & Lack of technical skills & 3.49 & 4.00 & 3.38 & 3.31 \\
\hline Q16 & $\begin{array}{l}\text { Poor information quality regarding energy } \\
\text { efficiency opportunities }\end{array}$ & 3.55 & 3.79 & 3.53 & 3.44 \\
\hline Q17 & Lack of budget funding & 4.11 & 4.14 & 4.18 & 4.00 \\
\hline Q18 & Slim organization & 3.42 & 4.07 & 3.41 & 2.88 \\
\hline Q19 & $\begin{array}{l}\text { Difficulties in obtaining information about the } \\
\text { energy consumption of purchased equipment }\end{array}$ & 3.40 & 3.79 & 3.32 & 3.19 \\
\hline Q20 & $\begin{array}{l}\text { Cost of identifying opportunities/analysing } \\
\text { cost effectiveness and tendering }\end{array}$ & 3.57 & 3.86 & 3.53 & 3.31 \\
\hline Q21 & Possible poor performance of equipment & 3.37 & 3.29 & 3.24 & 3.69 \\
\hline Q22 & Other priorities for capital investments & 3.89 & 4.00 & 3.94 & 3.81 \\
\hline Q23 & Access to capital & 3.65 & 4.14 & 3.53 & 3.56 \\
\hline & Average value & 3.47 & 3.67 & 3.46 & 3.33 \\
\hline
\end{tabular}


Table VII. Perceived barriers - by firm's size- Analysis of correlations

\begin{tabular}{|c|c|c|c|c|c|c|c|c|c|c|c|c|c|c|c|c|c|c|c|c|c|c|c|}
\hline & Q1 & Q2 & Q3 & Q4 & Q5 & Q6 & Q7 & Q8 & Q9 & Q10 & Q11 & Q12 & Q13 & Q14 & Q15 & Q16 & Q17 & Q18 & Q19 & Q20 & Q21 & Q22 & Q23 \\
\hline Q1 & - & $\begin{array}{c}0.58 \\
\end{array}$ & 0.39 & 0.35 & \begin{tabular}{|c|c|}
0.71 \\
\end{tabular} & 0.43 & 0.06 & 0.51 & 0.13 & 0.17 & $\begin{array}{ll}0.24 \\
\end{array}$ & $\begin{array}{ll}0.38 \\
\end{array}$ & 0.25 & 0.31 & 0.21 & $\begin{array}{l}0.06 \\
\end{array}$ & 0.35 & 0.23 & \begin{tabular}{|c|}
0.19 \\
\end{tabular} & 0.06 & $\begin{array}{l}0.29 \\
\end{array}$ & $\begin{array}{l}0.29 \\
\end{array}$ & $\begin{array}{l}0.41 \\
\end{array}$ \\
\hline Q2 & & - & 0.18 & 0.41 & 0.52 & 0.46 & 0.40 & 0.24 & 0.40 & 0.33 & 0.27 & 0.35 & 0.05 & 0.32 & 0.14 & 0.20 & 0.62 & 0.41 & 0.23 & 0.19 & 0.46 & 0.22 & 0.48 \\
\hline Q3 & & & - & 0.37 & 0.22 & 0.11 & 0.39 & 0.22 & 0.07 & 0.00 & -0.05 & 0.14 & 0.33 & 0.44 & 0.21 & -0.10 & 0.26 & 0.37 & 0.60 & 0.24 & 0.25 & 0.45 & 0.39 \\
\hline Q4 & & & & - & 0.31 & 0.38 & 0.43 & 0.37 & 0.17 & 0.52 & 0.53 & 0.28 & 0.15 & 0.43 & 0.36 & 0.13 & 0.43 & 0.51 & 0.64 & 0.06 & 0.26 & 0.25 & 0.27 \\
\hline Q5 & & & & & - & 0.53 & 0.21 & 0.64 & 0.29 & 0.30 & 0.39 & 0.48 & 0.29 & 0.44 & 0.27 & 0.30 & 0.56 & 0.34 & 0.16 & 0.13 & 0.39 & 0.44 & 0.47 \\
\hline Q6 & & & & & & - & 0.33 & 0.65 & 0.42 & 0.47 & 0.39 & 0.32 & 0.13 & 0.34 & 0.49 & 0.42 & 0.54 & 0.33 & 0.02 & 0.28 & 0.45 & 0.30 & 0.74 \\
\hline Q7 & & & & & & & - & 0.06 & 0.26 & 0.23 & 0.12 & 0.14 & 0.22 & 0.48 & 0.30 & 0.37 & 0.54 & 0.36 & 0.44 & 0.13 & 0.30 & 0.55 & 0.43 \\
\hline Q8 & & & & & & & & - & 0.24 & 0.50 & 0.43 & 0.38 & 0.35 & 0.35 & 0.48 & 0.39 & 0.36 & 0.41 & 0.13 & 0.35 & 0.31 & 0.06 & 0.47 \\
\hline Q9 & & & & & & & & & - & 0.34 & 0.25 & 0.44 & 0.05 & 0.55 & 0.23 & 0.37 & 0.38 & 0.19 & 0.17 & 0.64 & 0.56 & 0.16 & 0.33 \\
\hline Q10 & & & & & & & & & & - & 0.61 & 0.46 & 0.12 & 0.34 & 0.43 & 0.34 & 0.46 & 0.50 & 0.22 & 0.28 & 0.31 & 0.00 & 0.34 \\
\hline Q11 & & & & & & & & & & & - & 0.69 & 0.11 & 0.12 & 0.64 & 0.57 & 0.37 & 0.51 & 0.40 & 0.16 & 0.50 & 0.01 & 0.16 \\
\hline Q12 & & & & & & & & & & & & - & 0.36 & 0.26 & 0.55 & 0.58 & 0.44 & 0.52 & 0.42 & 0.31 & 0.53 & 0.12 & 0.21 \\
\hline Q13 & & & & & & & & & & & & & - & 0.33 & 0.27 & 0.24 & 0.52 & 0.38 & 0.26 & 0.21 & 0.31 & 0.37 & 0.33 \\
\hline Q14 & & & & & & & & & & & & & & - & 0.16 & 0.17 & 0.47 & 0.42 & 0.23 & 0.47 & 0.35 & 0.55 & 0.41 \\
\hline Q15 & & & & & & & & & & & & & & & - & 0.60 & 0.36 & 0.53 & 0.38 & 0.31 & 0.52 & 0.17 & 0.37 \\
\hline Q16 & & & & & & & & & & & & & & & & - & 0.30 & 0.33 & 0.11 & 0.38 & 0.51 & 0.00 & 0.22 \\
\hline Q17 & & & & & & & & & & & & & & & & & - & 0.45 & 0.26 & 0.17 & 0.47 & 0.44 & 0.66 \\
\hline Q18 & & & & & & & & & & & & & & & & & & - & 0.54 & 0.38 & 0.52 & 0.37 & 0.37 \\
\hline Q19 & & & & & & & & & & & & & & & & & & & - & 0.15 & 0.31 & 0.34 & 0.16 \\
\hline Q20 & & & & & & & & & & & & & & & & & & & & - & 0.39 & 0.16 & 0.49 \\
\hline Q21 & & & & & & & & & & & & & & & & & & & & & - & 0.19 & 0.32 \\
\hline Q22 & & & & & & & & & & & & & & & & & & & & & & - & 0.53 \\
\hline Q23 & & & & & & & & & & & & & & & & & & & & & & & - \\
\hline
\end{tabular}


Table VIII. Perceived barriers - by alloy.

\begin{tabular}{|c|c|c|c|c|}
\hline Operational difficulty & $\begin{array}{l}\text { Average } \\
\text { Score }\end{array}$ & Cast Iron & Cast Steel & Aluminium \\
\hline Conflicts of interest within the company & 2.83 & 2.88 & 2.64 & 2.67 \\
\hline Long decision chains & 2.88 & 2.82 & 3.07 & 2.53 \\
\hline Cost of staff replacement/retirement/retraining & 2.95 & 3.00 & 2.86 & 2.73 \\
\hline Department or workers not accountable for energy costs & 3.72 & 3.61 & 3.86 & 3.60 \\
\hline Energy manager lacks influence & 3.54 & 3.79 & 3.21 & 3.13 \\
\hline Uncertainty regarding the company's future & 3.14 & 3.12 & 3.07 & 3.20 \\
\hline Cost of production disruption/hassle/inconvenience & 3.69 & 3.42 & 3.79 & 4.00 \\
\hline Low priority given to energy management & 3.32 & 3.45 & 2.93 & 3.33 \\
\hline Lack of sub-metering & 3.51 & 3.33 & 3.07 & 4.27 \\
\hline Lack of staff awareness & 3.54 & 3.55 & 3.29 & 3.67 \\
\hline $\begin{array}{l}\text { Energy objectives not integrated into operating/maintenance or } \\
\text { purchasing procedures }\end{array}$ & 3.57 & 3.67 & 3.43 & 3.33 \\
\hline Technology is inappropriate at this site & 3.25 & 3.42 & 2.86 & 2.93 \\
\hline Lack of time or other priorities & 3.71 & 3.67 & 3.64 & 3.67 \\
\hline Technical risks such as risk of production disruptions & 3.66 & 3.73 & 3.21 & 3.67 \\
\hline Lack of technical skills & 3.49 & 3.61 & 2.86 & 3.73 \\
\hline Poor information quality regarding energy efficiency opportunities & 3.55 & 3.45 & 3.29 & 3.80 \\
\hline Lack of budget funding & 4.11 & 4.06 & 4.21 & 3.93 \\
\hline Slim organization & 3.42 & 3.30 & 3.29 & 3.47 \\
\hline $\begin{array}{l}\text { Difficulties in obtaining information about the energy consumption of } \\
\text { purchased equipment }\end{array}$ & 3.40 & 3.33 & 3.36 & 3.40 \\
\hline $\begin{array}{l}\text { Cost of identifying opportunities/analysing cost effectiveness and } \\
\text { tendering }\end{array}$ & 3.57 & 3.42 & 3.36 & 3.93 \\
\hline Possible poor performance of equipment & 3.37 & 3.55 & 2.86 & 3.40 \\
\hline Other priorities for capital investments & 3.89 & 3.82 & 3.86 & 3.93 \\
\hline Access to capital & 3.65 & 3.45 & 3.86 & 3.80 \\
\hline Average value & 3.47 & 3.45 & 3.30 & 3.48 \\
\hline
\end{tabular}


Table IX. Perceived barriers - Cast Iron enterprises - Analysis of correlations

\begin{tabular}{|c|c|c|c|c|c|c|c|c|c|c|c|c|c|c|c|c|c|c|c|c|c|c|c|}
\hline & Q1 & Q2 & Q3 & $\mathrm{Q} 4$ & Q5 & $\mathrm{Q} 6$ & $\mathrm{Q} 7$ & Q8 & Q9 & Q10 & Q11 & Q12 & Q13 & Q14 & Q15 & Q16 & Q17 & Q18 & Q19 & Q20 & Q21 & $\mathrm{Q} 22$ & Q23 \\
\hline Q1 & - & 0.55 & 0.21 & 0.22 & 0.59 & 0.37 & 0.05 & 0.36 & 0.01 & $\begin{array}{l}0.38 \\
\end{array}$ & 0.05 & $\begin{array}{l}0.24 \\
\end{array}$ & 0.02 & 0.28 & 0.15 & -0.23 & 0.19 & 0.15 & $\begin{array}{l}-0.13 \\
\end{array}$ & $\begin{array}{l}-0.08 \\
\end{array}$ & $\begin{array}{c}-0.04 \\
\end{array}$ & 0.10 & 0.24 \\
\hline Q2 & & - & 0.16 & 0.22 & 0.63 & 0.46 & 0.39 & 0.43 & 0.35 & 0.54 & 0.33 & 0.42 & 0.21 & 0.40 & 0.48 & 0.28 & 0.56 & 0.41 & 0.19 & 0.10 & 0.46 & 0.28 & 0.57 \\
\hline Q3 & & & - & 0.41 & 0.28 & 0.13 & 0.33 & 0.37 & -0.14 & 0.30 & 0.03 & 0.13 & 0.43 & 0.28 & 0.17 & -0.07 & 0.26 & 0.38 & 0.20 & -0.15 & -0.09 & 0.40 & 0.13 \\
\hline Q4 & & & & - & 0.28 & 0.52 & 0.33 & 0.31 & 0.12 & 0.39 & 0.39 & 0.34 & 0.30 & 0.42 & 0.21 & 0.26 & 0.35 & 0.33 & 0.41 & 0.17 & 0.38 & 0.14 & 0.16 \\
\hline Q5 & & & & & - & 0.51 & 0.24 & 0.52 & 0.25 & 0.50 & 0.05 & 0.39 & 0.02 & 0.58 & 0.20 & 0.14 & 0.58 & 0.20 & 0.04 & -0.06 & 0.14 & 0.33 & 0.61 \\
\hline Q6 & & & & & & - & 0.36 & 0.46 & 0.24 & 0.60 & 0.43 & 0.34 & 0.16 & 0.37 & 0.39 & 0.33 & 0.62 & 0.44 & -0.03 & 0.12 & 0.34 & 0.45 & 0.56 \\
\hline Q7 & & & & & & & - & 0.24 & 0.17 & 0.34 & 0.30 & 0.21 & 0.44 & 0.29 & 0.49 & 0.44 & 0.53 & 0.37 & 0.54 & 0.22 & 0.42 & 0.36 & 0.33 \\
\hline Q8 & & & & & & & & - & 0.19 & 0.72 & 0.33 & 0.29 & 0.44 & 0.24 & 0.44 & 0.24 & 0.44 & 0.41 & 0.16 & 0.25 & -0.04 & 0.09 & 0.48 \\
\hline Q9 & & & & & & & & & - & 0.28 & 0.34 & 0.52 & 0.14 & 0.37 & 0.28 & 0.48 & 0.36 & 0.07 & 0.31 & 0.54 & 0.38 & 0.22 & 0.40 \\
\hline Q10 & & & & & & & & & & - & 0.50 & 0.47 & 0.52 & 0.21 & 0.45 & 0.31 & 0.61 & 0.36 & 0.10 & -0.05 & 0.17 & 0.27 & 0.48 \\
\hline Q11 & & & & & & & & & & & - & 0.37 & 0.45 & 0.04 & 0.58 & 0.48 & 0.41 & 0.33 & 0.27 & 0.31 & 0.29 & 0.12 & 0.18 \\
\hline Q12 & & & & & & & & & & & & & 0.41 & 0.19 & 0.31 & 0.56 & 0.47 & 0.18 & 0.43 & 0.22 & 0.56 & 0.05 & 0.42 \\
\hline Q13 & & & & & & & & & & & & & - & -0.04 & 0.46 & 0.37 & 0.41 & 0.37 & 0.53 & 0.20 & 0.31 & 0.34 & 0.28 \\
\hline Q14 & & & & & & & & & & & & & & - & 0.05 & 0.09 & 0.35 & 0.19 & 0.11 & 0.15 & 0.30 & 0.31 & 0.39 \\
\hline Q15 & & & & & & & & & & & & & & & - & 0.61 & 0.52 & 0.27 & 0.21 & 0.26 & 0.38 & 0.23 & 0.35 \\
\hline Q16 & & & & & & & & & & & & & & & & - & 0.47 & 0.16 & 0.41 & 0.36 & 0.62 & 0.07 & 0.34 \\
\hline Q17 & & & & & & & & & & & & & & & & & - & 0.41 & 0.26 & 0.03 & 0.40 & 0.43 & 0.78 \\
\hline Q18 & & & & & & & & & & & & & & & & & & - & 0.29 & 0.05 & 0.17 & 0.33 & 0.42 \\
\hline Q19 & & & & & & & & & & & & & & & & & & & - & 0.43 & 0.49 & 0.14 & 0.23 \\
\hline Q20 & & & & & & & & & & & & & & & & & & & & - & 0.33 & -0.05 & 0.20 \\
\hline Q21 & & & & & & & & & & & & & & & & & & & & & - & 0.22 & 0.33 \\
\hline Q22 & & & & & & & & & & & & & & & & & & & & & & & 0.46 \\
\hline Q23 & & & & & & & & & & & & & & & & & & & & & & & - \\
\hline
\end{tabular}


Table X. Perceived barriers - by energy audit.

\begin{tabular}{|c|c|c|c|}
\hline Operational difficulty & Average Score & $\begin{array}{c}\text { No Energy } \\
\text { Audit }\end{array}$ & Energy Audit \\
\hline Conflicts of interest within the company & 2.83 & 2.41 & 3.13 \\
\hline Long decision chains & 2.88 & 2.81 & 2.92 \\
\hline Cost of staff replacement/retirement/retraining & 2.95 & 2.78 & 3.08 \\
\hline Department or workers not accountable for energy costs & 3.72 & 3.44 & 3.92 \\
\hline Energy manager lacks influence & 3.54 & 3.37 & 3.66 \\
\hline Uncertainty regarding the company's future & 3.14 & 3.00 & 3.24 \\
\hline Cost of production disruption/hassle/inconvenience & 3.69 & 3.41 & 3.89 \\
\hline Low priority given to energy management & 3.32 & 3.15 & 3.45 \\
\hline Lack of sub-metering & 3.51 & 3.48 & 3.53 \\
\hline Lack of staff awareness & 3.54 & 3.37 & 3.66 \\
\hline $\begin{array}{l}\text { Energy objectives not integrated into operating/maintenance or purchasing } \\
\text { procedures }\end{array}$ & 3.57 & 3.30 & 3.76 \\
\hline Technology is inappropriate at this site & 3.25 & 3.19 & 3.29 \\
\hline Lack of time or other priorities & 3.71 & 3.63 & 3.76 \\
\hline Technical risks such as risk of production disruptions & 3.66 & 3.30 & 3.92 \\
\hline Lack of technical skills & 3.49 & 3.26 & 3.66 \\
\hline Poor information quality regarding energy efficiency opportunities & 3.55 & 3.63 & 3.50 \\
\hline Lack of budget funding & 4.11 & 4.19 & 4.05 \\
\hline Slim organization & 3.42 & 2.93 & 3.76 \\
\hline $\begin{array}{l}\text { Difficulties in obtaining information about the energy consumption of } \\
\text { purchased equipment }\end{array}$ & 3.40 & 3.11 & 3.61 \\
\hline Cost of identifying opportunities/analysing cost effectiveness and tendering & 3.57 & 3.41 & 3.68 \\
\hline Possible poor performance of equipment & 3.37 & 3.19 & 3.50 \\
\hline Other priorities for capital investments & 3.89 & 3.63 & 4.08 \\
\hline Access to capital & 3.65 & 3.67 & 3.63 \\
\hline Average value & 3.47 & 3.29 & 3.59 \\
\hline
\end{tabular}


Table XI. Perceived barriers - Enterprises that have previously conducted an energy audit- Analysis of correlations

\begin{tabular}{|c|c|c|c|c|c|c|c|c|c|c|c|c|c|c|c|c|c|c|c|c|c|c|c|}
\hline & Q1 & Q2 & Q3 & Q4 & Q5 & Q6 & Q7 & $\mathrm{Q} 8$ & Q9 & Q10 & Q11 & Q12 & Q13 & Q14 & Q15 & Q16 & Q17 & Q18 & Q19 & Q20 & Q21 & Q22 & Q23 \\
\hline Q1 & & 0.41 & 0.28 & 0.45 & 0.56 & 0.38 & 0.30 & $\begin{array}{l}0.44 \\
\end{array}$ & 0.16 & 0.33 & 0.27 & \begin{tabular}{|l|l|}
0.44 \\
\end{tabular} & 0.25 & 0.15 & 0.35 & 0.19 & 0.26 & 0.36 & 0.23 & 0.06 & $\begin{array}{ll}0.23 \\
\end{array}$ & $\begin{array}{l}0.14 \\
\end{array}$ & $\begin{array}{l}0.42 \\
\end{array}$ \\
\hline Q2 & & - & 0.21 & 0.20 & 0.56 & 0.45 & 0.35 & 0.26 & 0.25 & 0.43 & 0.36 & 0.33 & -0.01 & 0.29 & 0.29 & 0.30 & 0.61 & 0.28 & 0.20 & 0.16 & 0.33 & 0.01 & 0.35 \\
\hline Q3 & & & - & 0.35 & 0.39 & 0.09 & 0.22 & 0.35 & -0.05 & 0.26 & 0.14 & 0.09 & 0.31 & 0.38 & 0.20 & 0.11 & 0.41 & 0.27 & 0.45 & 0.19 & 0.25 & 0.24 & 0.29 \\
\hline Q4 & & & & - & 0.31 & 0.32 & 0.50 & 0.28 & 0.20 & 0.50 & 0.34 & 0.33 & 0.31 & 0.36 & 0.26 & 0.26 & 0.34 & 0.34 & 0.53 & 0.17 & 0.37 & 0.27 & 0.35 \\
\hline Q5 & & & & & - & 0.60 & 0.33 & 0.70 & 0.11 & 0.52 & 0.56 & 0.39 & 0.14 & 0.30 & 0.42 & 0.36 & 0.58 & 0.37 & 0.14 & 0.07 & 0.24 & 0.22 & 0.43 \\
\hline Q6 & & & & & & - & 0.22 & 0.49 & 0.20 & 0.44 & 0.45 & 0.36 & 0.00 & 0.11 & 0.45 & 0.35 & 0.53 & 0.15 & -0.07 & 0.09 & 0.41 & 0.25 & 0.51 \\
\hline Q7 & & & & & & & - & 0.21 & 0.29 & 0.36 & 0.28 & 0.36 & 0.34 & 0.33 & 0.53 & 0.47 & 0.49 & 0.45 & 0.60 & 0.21 & 0.39 & 0.41 & 0.53 \\
\hline Q8 & & & & & & & & - & 0.22 & 0.46 & 0.52 & 0.28 & 0.30 & 0.22 & 0.55 & 0.34 & 0.37 & 0.42 & 0.16 & 0.36 & 0.20 & -0.01 & 0.59 \\
\hline Q9 & & & & & & & & & - & 0.34 & 0.31 & 0.37 & 0.14 & 0.28 & 0.29 & 0.31 & 0.30 & 0.21 & 0.30 & 0.46 & 0.40 & 0.08 & 0.37 \\
\hline Q10 & & & & & & & & & & - & 0.40 & 0.36 & 0.37 & 0.43 & 0.38 & 0.40 & 0.64 & 0.52 & 0.27 & 0.32 & 0.36 & 0.10 & 0.52 \\
\hline Q11 & & & & & & & & & & & - & 0.41 & 0.29 & 0.16 & 0.46 & 0.50 & 0.53 & 0.45 & 0.24 & 0.31 & 0.46 & 0.13 & 0.37 \\
\hline Q12 & & & & & & & & & & & & - & 0.41 & 0.29 & 0.39 & 0.62 & 0.32 & 0.38 & 0.34 & 0.25 & 0.44 & 0.04 & 0.29 \\
\hline Q13 & & & & & & & & & & & & & - & 0.38 & 0.23 & 0.48 & 0.40 & 0.76 & 0.40 & 0.40 & 0.24 & 0.28 & 0.47 \\
\hline Q14 & & & & & & & & & & & & & & - & 0.27 & 0.53 & 0.42 & 0.44 & 0.30 & 0.47 & 0.41 & 0.25 & 0.22 \\
\hline Q15 & & & & & & & & & & & & & & & - & 0.71 & 0.29 & 0.44 & 0.33 & 0.41 & 0.59 & 0.09 & 0.58 \\
\hline Q16 & & & & & & & & & & & & & & & & - & 0.37 & 0.58 & 0.39 & 0.52 & 0.69 & 0.14 & 0.36 \\
\hline Q17 & & & & & & & & & & & & & & & & & - & 0.56 & 0.24 & 0.20 & 0.34 & 0.41 & 0.65 \\
\hline Q18 & & & & & & & & & & & & & & & & & & - & 0.50 & 0.41 & 0.35 & 0.33 & 0.49 \\
\hline Q19 & & & & & & & & & & & & & & & & & & & - & 0.41 & 0.40 & 0.26 & 0.34 \\
\hline Q20 & & & & & & & & & & & & & & & & & & & & - & 0.42 & -0.10 & 0.31 \\
\hline Q21 & & & & & & & & & & & & & & & & & & & & & - & 0.11 & 0.29 \\
\hline Q22 & & & & & & & & & & & & & & & & & & & & & & - & 0.40 \\
\hline Q23 & & & & & & & & & & & & & & & & & & & & & & & - \\
\hline
\end{tabular}


Table XII. Perceived barriers - by Countries

\begin{tabular}{|c|c|c|c|c|}
\hline Operational difficulty & $\begin{array}{l}\text { Average } \\
\text { Score }\end{array}$ & Sweden & Germany & France \\
\hline Conflicts of interest within the company & 2.83 & 3.60 & 2.81 & 2.20 \\
\hline Long decision chains & 2.88 & 3.05 & 2.69 & 2.60 \\
\hline Cost of staff replacement/retirement/retraining & 2.95 & 3.25 & 3.00 & 3.70 \\
\hline Department or workers not accountable for energy costs & 3.72 & 4.10 & 3.50 & 3.90 \\
\hline Energy manager lacks influence & 3.54 & 3.80 & 3.38 & 3.40 \\
\hline Uncertainty regarding the company's future & 3.14 & 3.40 & 2.88 & 3.10 \\
\hline Cost of production disruption/hassle/inconvenience & 3.69 & 4.00 & 3.44 & 3.80 \\
\hline Low priority given to energy management & 3.32 & 3.80 & 3.13 & 3.00 \\
\hline Lack of sub-metering & 3.51 & 3.40 & 3.13 & 3.70 \\
\hline Lack of staff awareness & 3.54 & 3.65 & 3.31 & 3.30 \\
\hline $\begin{array}{l}\text { Energy objectives not integrated into operating/maintenance or } \\
\text { purchasing procedures }\end{array}$ & 3.57 & 3.90 & 3.31 & 3.30 \\
\hline Technology is inappropriate at this site & 3.25 & 3.35 & 3.00 & 3.30 \\
\hline Lack of time or other priorities & 3.71 & 4.25 & 3.56 & 3.50 \\
\hline Technical risks such as risk of production disruptions & 3.66 & 3.95 & 3.31 & 3.70 \\
\hline Lack of technical skills & 3.49 & 4.15 & 3.31 & 3.30 \\
\hline Poor information quality regarding energy efficiency opportunities & 3.55 & 3.65 & 3.25 & 3.40 \\
\hline Lack of budget funding & 4.11 & 4.30 & 3.69 & 4.10 \\
\hline Slim organization & 3.42 & 4.00 & 2.94 & 3.20 \\
\hline $\begin{array}{l}\text { Difficulties in obtaining information about the energy consumption of } \\
\text { purchased equipment }\end{array}$ & 3.40 & 3.80 & 3.25 & 3.40 \\
\hline $\begin{array}{l}\text { Cost of identifying opportunities/analysing cost effectiveness and } \\
\text { tendering }\end{array}$ & 3.57 & 3.75 & 3.19 & 3.80 \\
\hline Possible poor performance of equipment & 3.37 & 3.50 & 3.44 & 2.90 \\
\hline Other priorities for capital investments & 3.89 & 4.25 & 3.75 & 3.90 \\
\hline Access to capital & 3.65 & 4.25 & 3.00 & 3.50 \\
\hline Average value & 3.47 & 3.79 & 3.23 & 3.39 \\
\hline
\end{tabular}




\section{Barriers vs firm's size}

\section{Access to capital? \\ 22. Other priorities for capital investments? \\ 21. Possible poor performance of equipment?}

20. Cost of identifying opportunities/analyzing cost effectiveness and tendering?

19. Difficulties in obtaining information about the energy consumption of...

18. Slim organization?

17. Lack of budget funding?

16. Poor information quality regarding energy efficiency opportunities?

15. Lack of technical skills?

14. Technical risks such as risk of production disruptions?

13. Lack of time or other priorities?

12. Technology is inappropriate at this site?

11. Energy objectives not integrated into operating/maintenance or purchasing..

10. Lack of staff awareness?

9. Lack of sub-metering?

8. Low priority given to energy management?

7. Cost of production disruption/hassle/inconvenience?

6. Uncertainty regarding the company's future?

5. Energy manager lack influence?

4. Dept./ Workers not accountable for energy costs?

3. Cost of staff replacement/retirement/retraining?

2. Long decision chains?

1. Conflicts of interest within the company?

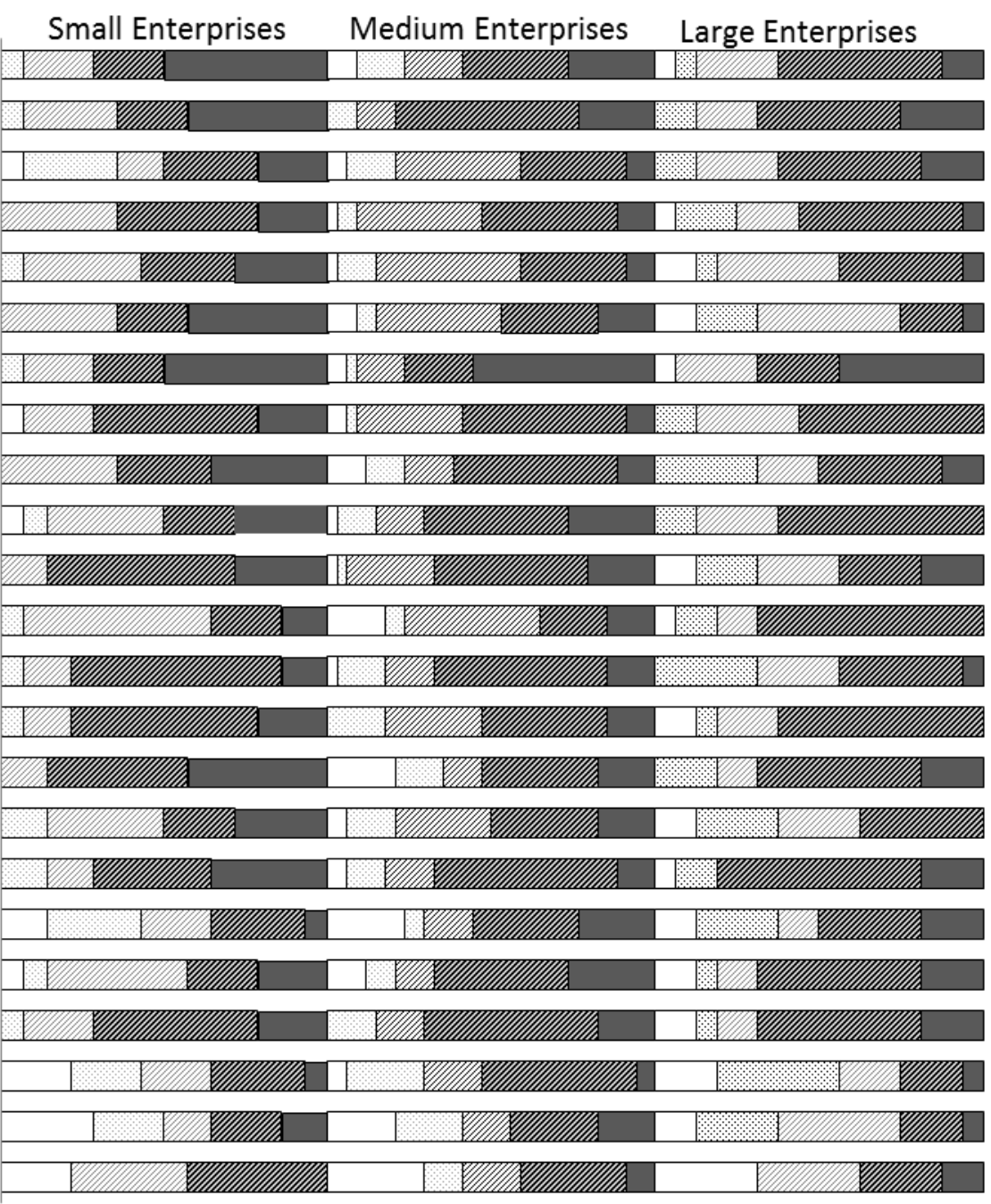

$\square$ not relevant $\square$ fairly relevant $\square$ relevant $\square$ very relevant $\square$ absolutely relevant 


\section{Barriers vs Alloy}

\section{Access to capital? \\ 22. Other priorities for capital investments?}

21. Possible poor performance of equipment?

20. Cost of identifying opportunities/analyzing cost effectiveness and tendering?

19. Difficulties in obtaining information about the energy consumption of...

18. Slim organization?

17. Lack of budget funding?

16. Poor information quality regarding energy efficiency opportunities?

15. Lack of technical skills?

14. Technical risks such as risk of production disruptions?

13. Lack of time or other priorities?

12. Technology is inappropriate at this site?

11. Energy objectives not integrated into operating/maintenance or purchasing..

10. Lack of staff awareness?

9. Lack of sub-metering?

8. Low priority given to energy management?

7. Cost of production disruption/hassle/inconvenience?

6. Uncertainty regarding the company's future?

5. Energy manager lack influence?

4. Dept./ Workers not accountable for energy costs?

3. Cost of staff replacement/retirement/retraining?

2. Long decision chains?

1. Conflicts of interest within the company?
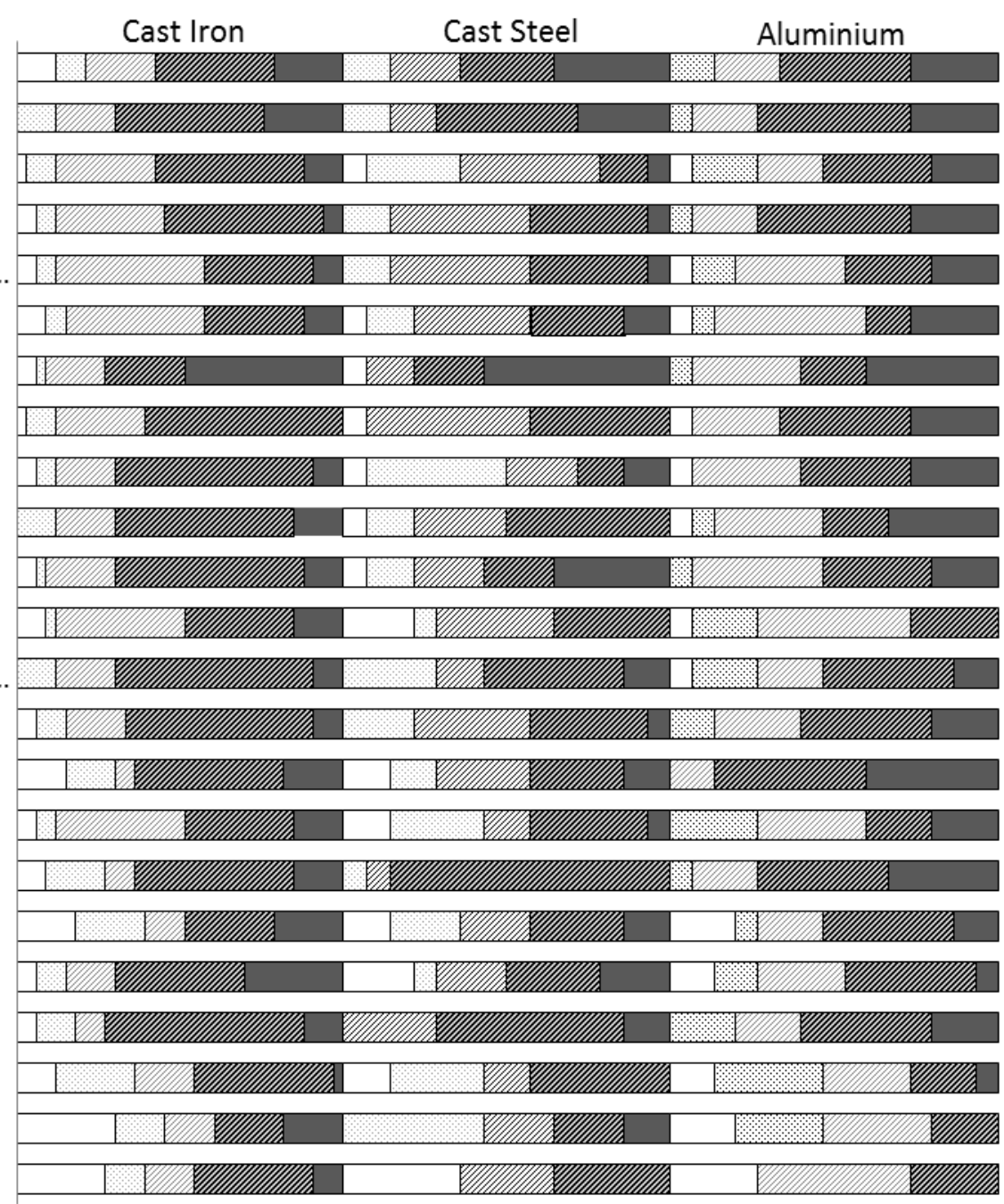


\title{
Barriers vs Energy audit
}

\author{
23. Access to capital? \\ 22. Other priorities for capital investments? \\ 21. Possible poor performance of equipment?
}

20. Cost of identifying opportunities/analyzing cost effectiveness and tendering?

19. Difficulties in obtaining information about the energy consumption of...

18. Slim organization?

17. Lack of budget funding?

16. Poor information quality regarding energy efficiency opportunities?

15. Lack of technical skills?

14. Technical risks such as risk of production disruptions?

13. Lack of time or other priorities?

12. Technology is inappropriate at this site?

11. Energy objectives not integrated into operating/maintenance or purchasing..

10. Lack of staff awareness?

9. Lack of sub-metering?

8. Low priority given to energy management?

7. Cost of production disruption/hassle/inconvenience?

6 . Uncertainty regarding the company's future?

5. Energy manager lack influence?

4. Dept./ Workers not accountable for energy costs?

3. Cost of staff replacement/retirement/retraining?

2. Long decision chains?

1. Conflicts of interest within the company?
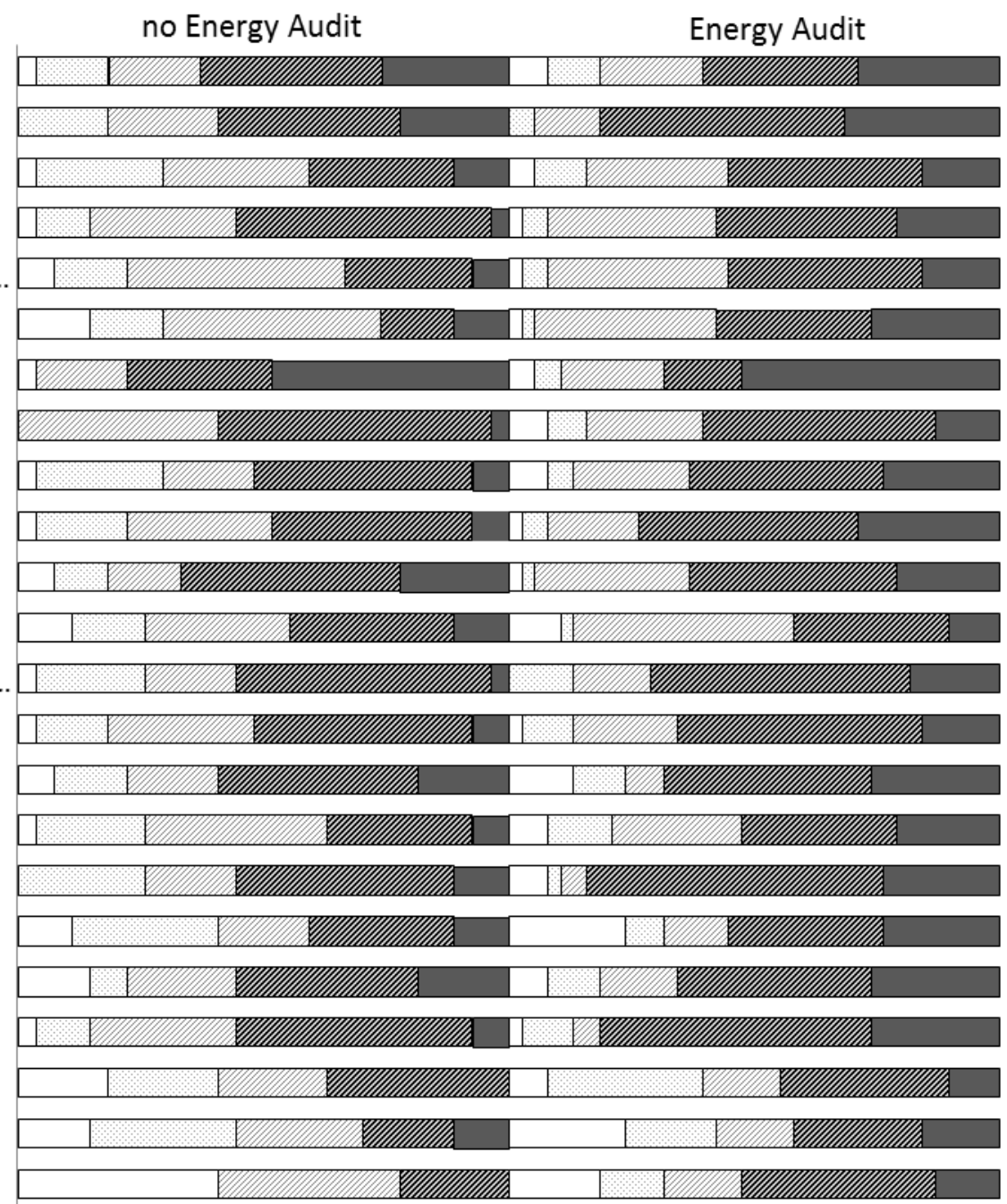

$\square$ not relevant $\square$ fairly relevant $\square$ relevant very relevant $\square$ absolutely relevant 


\section{Barriers vs Country}

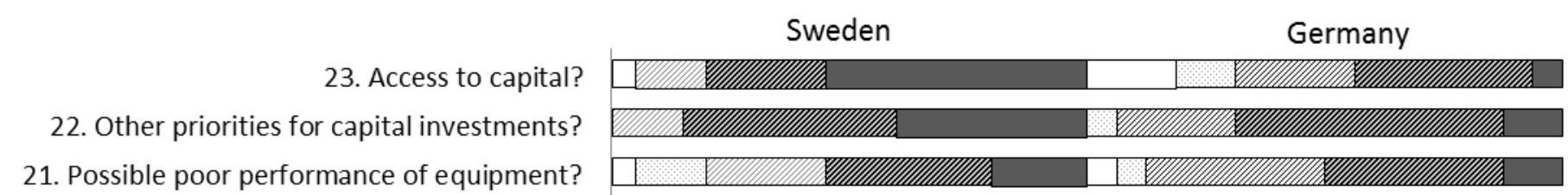

21. Possible poor performance of equipment?

20. Cost of identifying opportunities/analyzing cost effectiveness and tendering?

19. Difficulties in obtaining information about the energy consumption of...

18. Slim organization?

17. Lack of budget funding?

16. Poor information quality regarding energy efficiency opportunities?

15. Lack of technical skills?

14. Technical risks such as risk of production disruptions?

13. Lack of time or other priorities?

12. Technology is inappropriate at this site?

11. Energy objectives not integrated into operating/maintenance or purchasing...

10. Lack of staff awareness?

9. Lack of sub-metering?

8. Low priority given to energy management?

7. Cost of production disruption/hassle/inconvenience?

6. Uncertainty regarding the company's future?

5. Energy manager lack influence?

4. Dept./ Workers not accountable for energy costs?

3. Cost of staff replacement/retirement/retraining?

2. Long decision chains?

1. Conflicts of interest within the company?
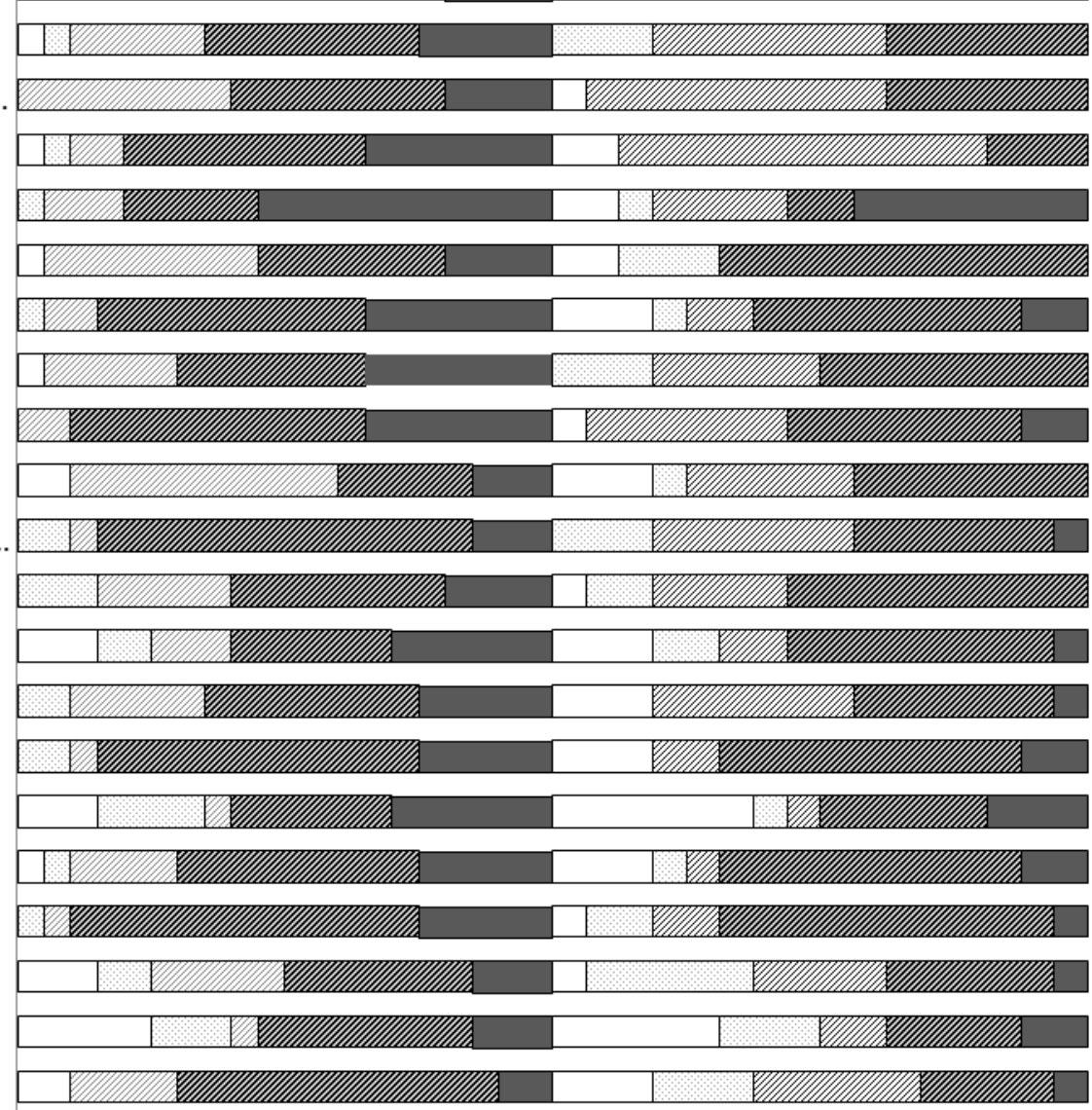

$\square$ not relevant $\square$ fairly relevant $\square$ relevant very relevant $\square$ absolutely relevant 